\title{
Glucose addiction in cancer therapy: advances and drawbacks
}

Sara Granja ${ }^{1,2}$, Céline Pinheiro ${ }^{1,2,3,4}$, Rui Manuel Reis ${ }^{1,2,4}$; Olga Martinho ${ }^{1,2}$ and Fátima Baltazar ${ }^{1,2}$

${ }^{1}$ Life and Health Sciences Research Institute (ICVS), School of Health Sciences, University of Minho, Braga, Portugal; '2ICVS/3B's - PT Government Associate Laboratory, Braga/Guimarães, Portugal; ${ }^{3}$ Barretos School of Health Sciences, Dr. Paulo Prata - FACISB, Barretos, Sao Paulo, Brazil; ${ }^{4}$ Molecular Oncology Research Center, Barretos Cancer Hospital, Barretos, Sao Paulo, Brazil

\section{*Corresponding author:}

Fátima Baltazar

Life and Health Sciences Research Institute (ICVS), School of Health Sciences, University of Minho, Campus de Gualtar, 4710-057 Braga, Portugal

Phone: +351253604828

Fax: +351253604820

E-mail: fbaltazar@ecsaude.uminho.pt

\begin{abstract}
Abbreviations
OXPHOS, oxidative phosphorylation; FDG-PET, fluoro-deoxy-glucose-positron emission tomography; RTK, Receptor Tyrosine Kinase; GLUT, glucose transporter; HKII, hexokinase II; PFK1, phosphofructokinase 1, PKM pyruvate kinase; LDH, lactate dehydrogenase; MCT, monocarboxylate transporter, PDK, pyruvate dehydrogenase kinase; PPP, pentose phosphate pathway; VDAC, voltagedependent anion channel; 2-DG, 2-Deoxy-D-glucose; 3-BP, 3-Bromopyruvate; PFKFB3, 6phosphofructo-2-kinase/fructose-2,6-bisphosphatase 3; ALL, acute lymphoblastic leukemia; Fru-2,6- $\mathrm{P}_{2}$ 2,6-bisphosphate; HIF-1 $\alpha$, hypoxia inducible factor 1, alpha subunit; ROS, reactive oxygen species; CHC, $\alpha$-cyano-4-hydroxycinnamate; DIDS, 4,40-di-isothiocyanostilbene-2,20-disulfonate; PDH, pyruvate dehydrogenase; DCA, Dichloroacetate acid; GIST, Gastrointestinal Stromal Tumors; CML, chronic myeloid leukemia CML; TCA, tricarboxylic acid cycle; CLL, chronic lymphocytic leukemia; ECAR, extracellular acidification rate; NSCLC, non-small-cell lung carcinoma; HNSCC, head and neck squamous cell carcinoma;
\end{abstract}




\begin{abstract}
In contrast to differentiated normal cells, which primarily use mitochondrial respiration to generate the energy needed for cellular processes, most cancer cells rely on glycolysis, even in sufficient oxygen conditions, a phenomenon known as the "Warburg effect" or aerobic glycolysis. In the last years, much attention to the metabolic reprogramming of cancer cells has been paid by many research groups and, as a result, this altered energy metabolism was recognized in 2011 as one of the "hallmarks of cancer". Aerobic glycolysis allows a rapid growth of tumor cells, with high rates of glucose consumption and lactic acid production, leading to cellular acidosis.

Metabolic reprogramming renders cancer cells dependent on specific metabolic enzymes or pathways that could be exploited in cancer therapy. The development of treatments that target tumor glucose metabolism is receiving renewed attention, with several drugs targeting metabolic pathways currently in clinical trials. However, the search for suitable targets may be limited by the high plasticity of the metabolic network that can induce compensatory routes. Moreover, deregulated glucose metabolism has been also shown as a prominent feature associated with resistance to either classical chemotherapy or oncogene-targeted therapies, strengthening the clinical potential of combining these therapies with glycolysis inhibitors.

The aim of this review is to compare the advances of the different therapeutic strategies targeting the glucose "addiction" of tumor cells, highlighting the potential of these findings to be translated into effective weapons against cancer. Further, we will also present and discuss recent evidence for the involvement of glucose metabolism as a compensatory response to the use of drugs that target different signaling pathways, in which combination with glycolysis inhibitors are potentially useful.
\end{abstract}

Keywords: Glucose, cancer metabolism, Warburg effect, targeted therapy, drug resistance 


\section{Introduction}

Reprograming energetic metabolism of cancer cells has been recently recognized by Hanahan and Weinberg in their review paper, as one of the "hallmarks of cancer" [1]. Altered cancer metabolism was first described by Otto Warburg in the 1920's, who observed that cancer cells exhibited high rates of glycolysis, independently of the levels of $\mathrm{O}_{2}$ [2]. This phenomenon is known as "aerobic glycolysis" or "Warburg effect" and has been described in many cancer cells [3-5]. Warburg proposed that cancer cells adopt the glycolytic phenotype as a result of damages in mitochondria at the level of oxidative phosphorylation (OXPHOS) [2]. Actually, mitochondrial alterations can be found at different levels, including decreased expression of mitochondrial protein complexes required for OXPHOS [6, 7], and mitochondrial mutations, leading to malfunction of OXPHOS [4]. Additionally, inactivation of p53, one of the most commonly mutated genes in cancer, may also trigger the Warburg effect by interfering with the activity of cytochrome c oxidase, a protein also involved in OXPHOS [8]. However, Warburg's hypothesis has been recently refuted. In fact, altered energy metabolism is an oncogenedriven cell adaptation to support cancer cell proliferation and survival [9, 10]. It was demonstrated that OXPHOS is still functional in many cancer cells, since inhibition of glycolysis can enhance OXPHOS activity [11].

Even though the metabolic phenotype adopted by cancer cells can vary within the of cancer type and even among subtypes of the same cancer, addiction to glucose metabolism appears to be a widespread characteristic of cancer cells. Despite not being a very efficient pathway (glycolysis only produces 2 ATP molecules per glucose molecule consumed in contrast to the 30 ATPs produced by mitochondrial activity), glycolysis provides rapid production of energy, metabolites for anabolic reactions and even confers higher aggressiveness to cancer cells by the metabolites produced, mainly lactic acid [12]. Cancer cells overcome this lower energetic efficiency, by increasing the rates of glycolysis, partly by upregulation of glucose transporters, especially GLUT1-4 and some key glycolytic enzymes [13].

Glycolytic metabolism has recently drawn more attention to cancer research scientists and even to the pharmaceutical industry, either in the diagnosis or therapeutic area. The high capacity to promote the uptake of glucose has been already explored as a diagnostic tool, in which a radioactive non-metabolizable glucose analogue is used to identify the tumoural areas in the body, in the noninvasive imaging technique, FDG-PET (fluoro-deoxy-glucose-positron emission tomography) scan. Considering the vital role of metabolic reprogramming for tumor growth, during the last years, many studies have demonstrated that targeting cancer bioenergetics is a very promising approach for anticancer therapy development. In fact, many compounds have been developed to selectively and effectively inhibit metabolic enzymes that are upregulated in several tumors. These inhibitors are currently at various stages of the clinical trial process and we will expose during this review the success and the failures of targeting glucose metabolism.

Further, and not less important, the use of FDG-PET scan has also shown the first evidence that alterations in glucose metabolism can occur upon patients' treatment with oncogene-targeted therapies [14-20]. That evidence has suggested that, on one hand, glycolytic alterations could be involved in tumors' response to targeted therapies and, on the other hand, glucose metabolism is 
regulated by protein kinases. In fact, the fast increase of research on the metabolic alterations of tumors has also improved our understanding of how oncogenes, specifically RTK pathways, are linked to altered cancer cell metabolism $[9,10]$. Prolonged glucose deprivation induces cellular stress, which has been known to contribute to oncogenic mutations [21] and activation of survival pathways, including the PI3K/AKT pathway [22]. Thus, unlike the growth factor dependence of normal cells, it is known that cancer cells can maintain growth factor-independent glycolysis and survival through expression of oncogenic kinases [23-25]. Knowing that, very recent publications have demonstrated, in preclinical models, that metabolic rewiring of cancer cells can potentially drive resistance to targeted therapies, which will be discussed in detail in this review.

\section{Glucose metabolism as target for cancer therapy}

Different steps of the glucose metabolic pathway have been explored in diverse cancer models and some drugs against this pathway already entered clinical trials. The main targets include the glucose transporters 1.3 and 4 (GLUT1/3/4), hexokinase II (HKII), phosphofructokinase 1 (PFKF3B), pyruvate kinase 1 and 2 (PKM1/2), lactate dehydrogenase 5 (LDH5), monocarboxylate transporters (MCTs) and pyruvate dehydrogenase kinase (PDK) (see Figure 1).

\subsection{Glucose transporters (GLUT1, GLUT3 and GLUT4)}

The uptake of extracellular glucose is facilitated by the glucose transporter (GLUT) family proteins and, as a result, some of these family members have been described as commonly upregulated in cancer. The family comprises 14 members, being GLUT1 isoform the most well studied, showing overexpression in a variety of tumors, as well as a close association with tumor development and poor prognosis. Additional evidence indicates overexpression of other GLUT isoforms in cancer, especially GLUT3 and GLUT4 (reviewed in [13]). Thus, due to the fundamental role of glucose uptake in the glycolytic pathway, targeting glucose transporters is an attractive approach to inhibit tumor growth. Until recently, GLUT inhibitors showed no specificity, however, new compounds are now emerging.

\subsubsection{GLUT inhibitors}

\section{Flavonoids (phloretin and silybin)}

Phloretin is a natural phenol and has been shown to inhibit growth and trigger apoptosis in in vitro and in vivo models of a variety of tumor types, as a result of glucose transmembrane transport inhibition [26-30]. However, although frequently used as a specific GLUT inhibitor, phloretin has also shown activity as an inhibitor of the $\mathrm{Na}^{+}$/glucose cotransporters SGLT1 and SGLT2 [31]. Importantly, phloretin was shown to sensitize colon and leukemia cancer cells to daunorubicin treatment, overcoming drug resistance under hypoxia [32], and to potentiate paclitaxel anticancer activity in both in vitro an in vivo models of liver cancer [33]. More recently, phloretin was also described as an 
enhancer of $\gamma \delta$ T cells' killing effect on SW116 colon cancer cells [34], providing an additional anticancer mechanism for phloretin.

Another natural compound, silybin/silibinin, has gained much attention in the last years, and was recently shown to be a GLUT inhibitor [35]. Preclinical studies, including both in vitro and in vivo studies, showed very promising results (reviewed in [36]), and phase I and II clinical trials using this flavonoid have been concluded in prostate cancer (NCT00487721) [37, 38] and advanced hepatocellular carcinoma (NCT01129570) [39]. In prostate cancer, although the phase I trial showed no grade 4 toxicity, liver toxicity was the most common adverse effect [38]. In the phase II trial, 1 out of 6 patients showed grade 4 toxicity and low tissue penetration was observed, notwithstanding high blood levels, warranting additional studies, such as longer treatment durations, sustained-release formulations to increase silybin half-time or combination with chemotherapy [37]. In fact, preclinical studies have shown that silybin reverses drug resistance and shows synergism with chemotherapeutic drugs [40-48], and a phase II clinical trial to assess the efficacy of combined erlotinib and silybin in patients with EGFR mutant lung adenocarcinomas is currently recruiting patients (NCT02146118). Although described as an inhibitor of GLUT [35], many other antitumoral activities have been attributed to silybin, including inhibition of telomerase expression [49, 50] and activity [51], inhibition of Notch signaling [52, 53], suppression of nuclear factor kappa B activation [54], decrease of angiogenic modulators [55], among others (reviewed in [36]).

As mentioned, these natural compounds have several biological properties besides GLUT inhibition, rendering objective conclusions regarding the therapeutic value of glucose uptake inhibition difficult. For that, studies using specific GLUT inhibitors are warranted.

STF-31

Recently, a promising specific inhibitor of GLUT1 aroused from a high-troughput chemical synthetic lethal screen in renal cell carcinomas. In this study, a class of compounds, exemplified by STF-31, that targets loss of von Hippel-Lindau tumor suppressor gene by direct binding to GLUT1 was identified. These compounds specifically target glucose uptake, showing promising results both in vitro and in vivo, without in vivo toxicity to normal tissues [56]. Additionally, STF-31 was shown to selective eliminate human pluripotent stem cells (hPSCs), which show similarities with cancer cells, from mixed cultures, in an attempted to investigate if surface expression of GLUT1 is required for hPSC biology [57]. However, a very recent publication demonstrated that nicotinamide phosphoribosyltransferase (NAMPT) is the actual target of STF-31, while providing data that suggests that GLUT1 does not mediate the cytotoxic effects of STF-31-like compounds [58]. Therefore, further studies are warranted to define the activity of these compouds.

\section{WZB117}

WZB117 was also described as a specific inhibitor of GLUT1. This compound was shown to induce a dose-dependent decrease in glucose transport, a decrease in extracellular lactate levels as well as in intracellular ATP in cancer cells, accompanied by a reduction of GLUT1 and glycolytic enzyme levels. Additionally, WZB117 induced cell cycle arrest in vitro and inhibited tumor growth in vivo, 
with relatively low toxicity. Importantly, exogenous ATP rescued in vitro cancer cell growth, indicating that intracellular ATP reduction plays an important role in WZB117-induced growth inhibition. Also, WZB117 showed synergistic effects when combined with cisplatin or paclitaxel [59]. Similarly to STF-31, WZB117 was also shown to selectively eliminate hPSCs from mixed cultures, effect attributed to GLUT1 specific inhibition [57]. However, also similarly to STF-31, further studies are warranted to validate the activity of WZB117 as a specific inhibitor of GLUT1.

\section{HIV protease inhibitor therapy}

Studies addressing the mechanism involved in HIV protease inhibitors-induced insulin resistance demonstrated that these inhibitors, especially ritonavir, inhibit GLUT4, but not GLUT1, activity, both in vitro an in vivo [60,61]. This off-target activity of ritonavir has been explored in multiple myeloma cell lines, where ritonavir treatment decreased both glucose transport and proliferation in a dose-dependent manner. Also, ritonavir treatment sensitized cancer cells to doxorubicin treatment, showing a promising therapeutic potential of ritonavir-mediated GLUT4 inhibition in multiple myeloma [62].

From all the above, as well as additional data showing upregulation of GLUT3 in temozolomide-resistant glioblastoma cells [63], the use of combined therapies using glucose uptake inhibitors and standard chemotherapeutic agents seems the most promising approach to potentiate cancer therapy as well as overcome drug resistance.

\subsection{Hexokinase II (HKII)}

The first rate-limiting step in the glycolytic pathway consists in the phosphorylation of glucose to form glucose 6-phosphate, trapping glucose inside the cell to fuel both glycolysis and the pentose phosphate pathway (PPP). This reaction is provided by hexokinases (HK), a family of 4 members (I-IV); HKI and HKII are usually found in the outer membrane of mitochondria, HKIII is found in a perinuclear compartment and HKIV is found in the cytoplasm. Is has been described that mitochondrial location of HKI and HKII is largely dependent on interaction with the outer membrane voltage-dependent anion channel (VDAC) and that this location is a strategy for preferential access to ATP as well as insensitivity to negative regulation by glucose-6-phosphate. Importantly, the association of HK with VDAC interferes with the interaction of VDAC with the apoptotic inhibitor Bcl- $\mathrm{X}_{\mathrm{L}}$, contributing to apoptosis evasion (reviewed in [64]). HKII is the predominant isoform overexpressed in malignant tumors and the properties of this isoform that are on the basis for its upregulation over the other isoforms in cancer is reviewed elsewhere [65]. Importantly, since most normal mammalian tissues express very little HKII, with muscle, adipocytes and lung expressing low but significant levels [65], a therapeutic window to inhibit HKII without important on-target sideeffects is antecipated [66]. 


\subsubsection{HK inhibitors}

2-Deoxy-D-glucose (2-DG)

The glucose analogue 2-deoxy-D-glucose (2-DG) is the most widely used glycolysis inhibitor [67], being one of the most advanced clinical agent inhibiting cancer metabolism. It is phosphorylated to 2-DG-6-phosphate by HK but cannot be further metabolized, therefore inhibiting $\mathrm{HK}$ activity by noncompetitive inhibition. Although 2-DG is mainly described as a HK inhibitor, 2-DG-6-phosphate is a competitive inhibitor of enzymes that metabolize glucose-6-phosphate and 2-DG may also compete with glucose for GLUT, further inhibiting the glycolytic rate, NADH and lactate production, as well as decreasing ATP levels. Importantly, besides the expected anticancer effects of 2-DG, including in vitro inhibition of proliferation and colony formation as well as in vivo tumor growth inhibition, 2-DG induces apoptosis, autophagy, proteolytic events and endoplasmic reticulum stress (reviewed in [68]). As a competitive inhibitor, the single use of 2-DG is limited by the high concentrations necessary to compete with glycolytic pathway products [69], however, in vitro studies using combination of 2-DG and standard therapeutic agents such as cisplatin and docetaxel show that 2-DG may potentiate the effect of standard therapy $[64,67]$. The first use of 2-DG in humans as an anticancer drug dates back to 1958 [70] and there is no clinical trial currently is ongoing. Previous studies showed an improvement of radiotherapy effect if combined with 2-DG in brain tumors, with acceptable toxicity (reviewed in [71]), however, there are doubts if these studies used clinically relevant doses of 2-DG [72]. From the three 2-DG therapeutic clinical trials listed in the U.S. National Institutes of Health's database (NCT00096707, NCT00247403 and NCT00633087; clinicaltrials.gov), only one has been completed (NCT00096707). In this phase I clinical trial, the safety, tolerability, pharmacokinetics, and biologic effect of daily oral doses of 2-DG in combination with weekly docetaxel were evaluated in subjects with advanced solid tumors. After determining the 2-DG clinically tolerable dose, the most significant adverse effects were reversible hyperglycemia, gastrointestinal bleeding and reversible 3 QTc prolongation [73]. The other two clinical trials were not successful, as one was withdrawn prior to enrollment since the pharmaceutical company ceased drug manufacturing (NCT00247403) and the other was suspended due to slow accrual (NCT00633087), but was able to define a dose for phase II trials [74]. Therefore, 2-DG phase II/III clinical trials are warranted to progress beyond the current state.

\section{Lonidamine}

Lonidamine is a derivative of indazole-3-carboxylic acid and was firstly designed and synthesized to act as an antispermatogenic drug [75]; however, currently, this compound is vastly known thanks to its anticancer activity. In the early $80 \mathrm{~s}$, lonidamine was described as a specific inhibitor of mitochondrially bound hexokinase [76], but, more recently, other effects have been described for lonidamine, including inhibition of lactate transport and modification of membranes' permeability (reviewed in [77]). In fact, preclinical studies showed that lonidamine, besides inhibiting cancer cell energy metabolism [76], also induces apoptosis [78, 79], enhances the activity of standard anticancer drugs [80-83] and reverses chemoresistance [84, 85] (reviewed in [77]). A large number of 
clinical studies using lonidamine, alone or in combination with standard chemotherapeutic agents, were performed during the $80 \mathrm{~s}$ and $90 \mathrm{~s}$ in various tumor types, mainly lung and breast cancer (reviewed in [77]), and additional studies were performed more recently in breast cancer [86, 87], glioblastoma multiforme [88] and ovarian cancer [89]. Also, until recently, this compound was in phase II/III clinical studies for the treatment of benign prostatic hyperplasia (NCT00237536 and NCT00435448), however, the trials have been suspended due to hepatotoxicity [90].

Overall, although some studies showed encouraging results, an unequivocal clinical benefit of lonidamine use was not found.

Interestingly, lonidamine has also been shown to interfere with angiogenesis-related endothelial cell functions including proliferation, migration, invasion and morphogenesis, which may contribute to the antitumor effect of lonidamine observed in in vivo experiments and patients [91]. Finally, recent studies using paclitaxel/lonidamine loaded EGFR-targeted nanoparticles in in vitro and in vivo models of multidrug resistant breast and ovarian cancer showed that the nanocarrier system enhanced the therapeutic index of both drugs and decreased toxicity, indicating that this new delivery approach may be a promising strategy for treatment of multidrug resistant tumors [92-94].

\section{3-bromopyruvate (3-BP)}

The halogenated analog of pyruvate 3-bromopyruvate (3-BP) is the current leading HKII inhibitor [90]. This compound, similarly to the other HKII inhibitors, depletes cellular ATP reserves, decreasing ATP-binding cassette transporters (ABC transporters) activity and restoring drug retention in malignant cells. This leads to 3-BP-induced enhanced cancer cell sensitivity to anticancer drugs such as daunorubicin and doxorubicin, and inhibition of in vivo tumor growth, alone or combined with standard anticancer agents [95-98]. Also, ATP depletion by 3-BP reverses colon cancer cells' resistance to oxaliplatin and 5-fluorouracil treatment [99]. Although initially described as a HKII inhibitor more effective than 2-DG [100], GAPDH rather than HKII is the major target of 3-BP. Other targets have also been described for 3-BP, including pyruvate kinase, lactate dehydrogenase, endoplasmic reticulum and lysosomes (reviewed in [101, 102]). Importantly, massive parallel sequencing identified monocarboxylate transporter 1 (MCT1), which is frequently upregulated in cancer (reviewed in [103]) as the main determinant for 3-BP sensitivity, most probably by mediating 3BP uptake by cancer cells, being a potential biomarker for selection of 3-BP responsive tumors [104]. Following the promising results from both in vitro an in vivo studies (reviewed in [102]), recently, a 3BP case study was performed in a young adult patient presenting fibrolamellar hepatocellular carcinoma, who survived a much longer period than expected with an improved quality of life, as a result of treatment with 3-BP [105]. Despite all these promising results, 3-BP has not yet entered clinical trials.

Additionally, the three above-mentioned HKII inhibitors have been shown to increase in vitro sensitivity of acute lymphoblastic leukemia (ALL) cells to glucocorticoids, while 2DG was able to revert glucocorticoid resistance in both ALL cell lines and primary leukemia cells isolated from pediatric ALL [106]. 
Alternative approaches to target HK include targeting HKII-VDAC complexes, the plant hormone methyl jasmonate, Casiopeina II-gly synthetic compound and small hairpin RNA (reviewed in [64]).

\subsection{6-phosphofructo-2-kinase/fructose-2,6-bisphosphatase 3 (PFKFB3)}

One of the most critically regulated enzymes of glycolysis is 6-phosphofructo-1-kinase (PFK1), being fructose 2,6-bisphosphate (Fru-2,6- $\left.\mathrm{P}_{2}\right)$ a powerful activator of this enzyme. The levels of Fru2,6- $\mathrm{P}_{2}$ are controlled by a family of bifunctional enzymes (6-phosphofructo-2-kinase/fructose 2,6bisphosphatase; PFK-2/FBPase-2 or PFKFB), which are responsible for both the synthesis of Fru-2,6$\mathrm{P}_{2}$ from fructose 6-phosphate (PFK-2 domain) and hydrolysis of Fru-2,6- $\mathrm{P}_{2}$ to fructose 6-phosphate (FBPase-2 domain). Among the several isoenzimes that constitute PFKFB family, PFKFB3, due to its predominant kinase activity compared to phosphatase activity, is more likely to contribute to the high glycolytic activity of cancer cells (reviewed in [107]). In fact, several studies show upregulation of PFKFB3 in cancer cells [108-110], and silencing studies show a role of this enzyme in cell cycle, anchorage-independent growth and apoptosis suppression [111, 112]. Additionally, a role of PFKFB3 in vessel sprouting has been recently described [113].

\subsubsection{PFKFB3 inhibitors}

$3 P O$ and derivatives

Until very recently, the only specific inhibitor of PFKFB3 was 3-(3-pyridinyl)-1-(4pyridinyl)-2-propen-1-one, commonly known as 3PO [114]. This inhibitor was shown to decrease the intracellular concentrations of Fru-2,6- $\mathrm{P}_{2}$, leading to a decrease in glucose uptake, as well as in intracellular ATP and lactate. Also, in vitro use of 3PO inhibited the proliferation of several human cancer cells lines and showed selectivity for ras-transformed cells versus normal cells, while inhibition of tumor growth in vivo was also observed [114]. More recently, 3PO was shown to cause, besides a decrease in glucose consumption, an increase in autophagy [115]. The authors raised the hypothesis that 3PO-induced autophagy may protect cells from 3PO-induced apoptosis, defending the combined use of 3PO with inhibitors of autophagy for cancer treatment [115]. In the meantime, the 3PO derivative 1-(4-pyridinyl)-3-(2-quinolinyl)-2-propen-1-one (PFK15), which showed to be a more potent PFKFB3 inhibitor, was shown to rapidly induce apoptosis in transformed cells and suppresse tumor growth in Lewis lung carcinomas in syngeneic mice as well as in human xenograft tumors [116]. A phase I clinical trial using PFK15 was expected to initiate in 2013 [116]. Besides direct inhibition of cancer cell growth, additional effects of 3PO-induced inhibition of PFKFB3 include angiogenesis inhibition [117] and suppression of $\mathrm{T}$ cell activation [118], which may further contribute to the exploitation of PFKFB3 as a strategy for cancer therapy.

\subsection{Pyruvate kinase isozyme M2 (PKM2)}


The M1 isoform of PK (PKM1) is expressed in normal proliferating cells and tissues such as lung, retina, pancreatic islets, fat cells, while M2 isoform (PKM2) an alternatively spliced variant of M1, is expressed during embryonic development [119]. Moreover, this enzyme is overexpressed in many cancers and not in normal adult tissues making it a promising anti-cancer therapeutic target. PKM2 may be expressed either as an active tetramer or as a nearly inactive dimer PKM2 [120]. The balance between tetrameric and dimeric PKM2 conformation occurs in an oscillating form, subject to phosphorylation and allosteric regulation [121].

PKM2 has been reported to promote cell survival, cell migration and cell invasion in several types of cancer such as colon and gastric carcinoma cells. There is are also evidence suggesting that PKM2 could involved in cancer initiation and transformation (reviewed in [122]). Importantly, due to the higher expression of PKM2 in cancer, a clinical trial was created to determine in plasma and saliva if PKM2 could be a useful biomarker for pleural malignancies (NCT001130584). This study was already completed, unfortunately with no reported results. Given all these important functions, targeting PKM2 in cancer cells is an attractive approach and that, different inhibitors have been developed and tested with promising results.

\subsubsection{PKM2 inhibitors}

\section{$T L N-232 / C A P-232$}

Thallion Pharmaceuticals initiated in 2007 the first clinical trial with the PKM2 inhibitor TLN-232/CAP-232, a seven amino-acid peptide. This phase II clinical trial (NCT00422786) was conducted in patients with refractory metastatic renal cell carcinoma and promising results were reported in 2008. Thus, the drug TLN-232 was generally safe and well tolerated and the outcome was that two out of the 3 patients complete the study with stable disease. Thallion's studies suggest that the anti-cancer activity of TLN-232 is mediated by a mechanism involving the translocation of PKM2 to the nucleus, resulting in cell death. This compound was also in phase II clinical trial for the treatment of metastatic melanoma (NCT00735332), however, the trial has been suspended due to an ongoing dispute with the licensor. Additionally, the inhibition of PKM2 has become controversial since some studies showed that inhibition of PKM2 by post-translational modifications could support cancer cell proliferation and different PKM2 activators had an inhibitory effect on tumorigenesis [123, 124]. PKM2 contains an inducible nuclear translocation signal in its C-domain, making its role complex $[123,125]$. Furthermore, this enzyme is involved in a variety of pathways with potential to perform multiple non-glycolytic functions that could be the base to explain the controversial results. Thus, it is urgent to explore the multidimensional role of this protein to find new therapeutic approaches or to identify possible metabolic weaknesses that could be exploited using drug combination.

\subsection{Lactate dehydrogenase A (LDHA)}

LDH belong to a family of tetrameric enzymes that are formed by two major subunits, $\mathrm{M}$ and $\mathrm{H}$, which can assemble into five different combinations. Two of the resulting isoforms are 
homotetramers - LDH-1 (H4) and LDH-5 (M4) also known as LDHB and LDHA, respectively [126, 127]. LDHB is ubiquitously expressed in normal tissue an it is responsible for the conversion of lactate into pyruvate, while, LDHA that is induced by the hypoxia inducible factor $1 \alpha(\mathrm{HIF}-1 \alpha)$ is found in highly glycolytic tissues [128]. Therefore, LDHA plays a key role in regulating glycolysis by catalysing the final step of anaerobic glycolysis, converting pyruvate into lactate for the regeneration of $\mathrm{NAD}+$ to accelerate glycolysis and facilitates the efficiency of these metabolic pathway in tumor cells reducing their dependency on oxygen [129]. The levels of LDHA are elevated in many malignant tumors and is associated with tumor proliferation and malignant growth with potential implications in cancer therapy. Moreover, monitoring serum LDH levels have been shown to be a useful prognostic tool [130]. Thereby, inhibition of LDHA expression could potentially interfere with cancer development and indeed there are already molecules that have been identified to inhibit LDH.

\subsubsection{LDHA inhibitors}

\section{Gossypol/AT-101 and derivates}

Gossypol (also known as AT-101), is a non-selective inhibitor of LDH that blocks binding to $\mathrm{NADH}$, with a Ki of $1.9 \mu \mathrm{M}$ for LDHA. This drug was initially developed as a therapy against malaria [131] and it was firstly used in humans as a male contraceptive. Previous clinical studies showed that gossypol is well-tolerated with the most common adverse events being gastrointestinal toxicities and fatigue. A phase I/II clinical oncology trial (NCT00773955) developed in patients with chemotherapysensitive relapsed small cell lung carcinomas revealed disappointing results [132]. Moreover, a phase I/II study (NCT00397293) of AT-101 in combination with topotecan in patients with the same type of cancer was also designed, but it was interrupted because since it did not meet its primary endpoints [133]. Currently, no clinical trial as monotherapy agent is ongoing, yet some new studies in combination with other drugs are starting to recruit participants diagnosed with lymphocytic leukemia and non-small cell lung cancer (NCT01003769 and NCT01977209, respectively). Unfortunately, due to the two aldehyde groups, gossypol has a chemical structure highly reactive and can chelate metal ions. This results in biological system toxicity and different side effects such as cardiac arrhythmias, hypokalemia, renal failure, muscle weakness and sometimes paralysis [126].

Additionally, 3-dihydroxy-6-methyl-7-(phenylmethyl)-4-propylnaphthalene-1-carboxylic acid (FX11), has been identified through screening of a bank of compounds derived from gossypol. This compound has been shown to increase the activity of unhealthy mitochondria, decreasing ATP levels cell, proliferation, and increasing oxygen consumption, reactive oxygen species (ROS) production and cell death [134]. However, there are still no studies reporting of FX11 in the clinical setting, probably because of its highly reactive catechol portion and off-target effects [126, 135].

\section{Other LDH inhibitors}

Additionally, there are other references to other LDH inhibitors that have been shown promising in vitro results in targeting cancer. One of the most known and studied LDH inhibitor is so 
far oxamic acid [126]. In vitro experiments have shown the potential of oxamic acid in tumor cells, however, since this compound has a poor cell permeability, the concentration used is high and cannot be reached in vivo. Likewise, the simple and small structure of oxamate confers several disadvantages, making it a nonspecific LDH-inhibitor.

Furthermore, Galloflavin, has been recently identified as a novel inhibitor of human LDH isoforms and has been shown to induce apoptosis of hepatocellular carcinoma cell lines, and inhibit breast cancer cell proliferation [127]. Galloflavin proved to be less cytotoxic to normal cells, and to be well tolerated by mice [126]. Clearly, these promising results encourage further studies with this molecule.

Recently, N-hydroxy-2-carboxy-substituted indole compounds have been identified as specific LDHA inhibitors, which can reduce lactate production by acting as competitors of NADH and pyruvate. However, these new natural compounds apparently have low stability [135], and further studies are needed to support their potential as anti-cancer drugs.

\subsection{Monocarboxylate transporters}

Monocarboxylate transporters (MCTs), constitute a family of plasma membrane transporters with 14 members already identified, albeit, only the first four isoforms are able to catalyse the protoncoupled transport of monocarboxylates, playing an important role in cell metabolism. The expression of each isoform depends on its function and with the metabolic requests of each tissue (reviewed in[136]).

MCT1 and MCT4 are commonly overexpressed by cancer cells to maintain lactate and $\mathrm{pH}$ homeostasis [137]. Taking into account the tumor microenvironmental scenario and molecular events that occur in carcinogenesis the importance of these lactate transporters makes them attractive targets in cancer therapy. Considering the cell-cell lactate shuttle in cancer cells described by Sonveaux and co-workers [138], where MCT1 has a crucial role as the gatekeeper of metabolic symbiosis of cancer cells, by importing lactate into oxidative cells, targeting of MCT1 will have important implications in cancer homeostasis. Also, inhibition of MCTs will have a direct effect in lactate transport, interfering with intracellular $\mathrm{pH}$ homeostasis and also with the acidic microenvironment.

\subsubsection{MCT inhibitors}

\section{AZD3965 MCT1/2 specific inhibitors}

A new class of specific and high-affinity inhibitors of MCT1 have recently been developed by AstraZeneca. The authors found it to be active against MCT1 and MCT2 but not MCT4 [139]. Specifically, AR-C155858 compound seems to exert its function by binding MCT1 from the cytosolic side. The use of chimeric transporters combining different domains of MCT1 and MCT4 revealed that the binding site for the inhibitor is contained within the C-terminal of MCT1, and involves the transmembrane domains 7-10 [139]. 
A specific inhibitor of MCT1/2, AZD3965 (NCT01791595), is now being tested in a phase I/II clinical trial in patients with advanced solid tumors (prostate and gastric) or lymphomas.

\section{Classic inhibitors}

There are numerous non-physiological competitive inhibitors described that are known to inhibit the function of MCTs [140]. Several studies have demonstrated the affinity and specificity of each inhibitor to each MCT isoform. These include aromatic compounds such as $\alpha$-cyano-4hydroxycinnamate $(\mathrm{CHC})$ and phenylpyruvate, stilbene disulfonates such as 4,40-diisothiocyanostilbene-2,20-disulfonate (DIDS) and 4,40-dibenzamidostilbene-2,20-disulfonate (DBDS) and bioflavonoids such as phloretin and quercetin. These inhibitors inhibit MCTs with higher affinity for MCT1 and 2, although, they have the ability to also inhibit other transporters at higher concentrations. Moreover, it has been already identified other targets for these inhibitors. CHC has been shown to be a potent inhibitor of the mitochondrial pyruvate transporter, whereas DIDS and DBDS inhibit the chloride/bicarbonate exchanger AE1. Phloretin and quercetin are also non-specific inhibitors [103], even thought, several studies describe how these inhibitors affect lactate transport. Recently, our group showed that $\mathrm{CHC}$ reduces lactate efflux, cell proliferation, invasion and migration and increase cell death in in vitro glioma [141] and breast tumor cells [142]. This effect was also corroborate using iRNA experiments $[141,142]$. Cell death induced by CHC was also observed in colorectal and cervix carcinoma in in vitro and in vivo models [138]. Nevertheless, inhibition of one MCT isoform can be compensated by another MCT isoform, leading to resistance to treatment [143].

Previous results show that CD147 and MCTs are co-expressed in human cancer tissues [141, 143-149]. Moreover, results published by our group showed that the prognostic value of CD147 appears to be associated with its co-expression with MCT1 in breast cancer [150]. Therefore, targeting CD147 to inhibit MCTs appears to be a rational approach.

In this context, CD147 silencing has been reported to inhibit MCT1/MCT4 function decreasing lactate efflux [151] and consequently reducing pHi [143, 152, 153] and reducing the malignant potential of cancer cells in vivo $[143,153]$. Moreover, CD147 expression is also associated with tumor progression, prognosis and chemoresistance [154], however, there are no clinical studies with respect to inhibition of CD147 in cancer patients, probably because effective and specific inhibitors are scarce. Recently exciting clinical progress has been made by the development of CD147directed monoclonal antibodies [155].

\subsection{Pyruvate dehydrogenase kinase 1 (PDK1)}

PDK regulates the enzymatic activity of pyruvate dehydrogenase (PDH), the enzyme responsible for pyruvate conversion into acetyl-CoA to feed the tricarboxylic acid (TCA) cycle. Four isomeric forms of PDK (PDK1-4) exist having tissue specific expression, singular activities, and different phosphorylation rates (reviewed in [156]). Under hypoxia conditions, PDK1 phosphorylates the E1 $\alpha$ subunit of PDH, inhibiting its catalytic activity and consequently oxidative phosphorylation 
[157]. OXPHOS impairment in cancer is predominantly due to the inhibition of PDH by PDK being this enzyme that controls the fate of pyruvate. Thus, and following the idea that many cancer cells depend on glycolysis for their energy demands, inhibiting PDK and consequently this metabolic pathway could be the "Achilles' heel" for these cells.

\subsubsection{PDK inhibitors}

\section{Dichloroacetate (DCA)}

Dichloroacetate (DCA) has been known for a long time as a PDK inhibitor [158] and was already used in the late 80 's in clinical trials. This pyruvate mimetic was shown to occupy the pyruvate-binding site of PDK2, which is largely conserved among PDKs, therefore inhibiting non-selectively but with different potencies all PDK isoforms [159]. By inhibiting PDK, this drug preserves the PDH active form, promotes pyruvate-to-acetyl-CoA flux and reduces pyruvate-to-lactate conversion, thereby facilitating OXPHOS. This will lead to increased mitochondria depolarisation, increased ROS and apoptosis is induced in cancer cells with both cytochrome $\mathrm{c}$ and apoptosis-inducing factor efflux from the mitochondria [160]. This results in a decrease in tumor growth both in vitro and in vivo in xenotransplant models [161]. Preclinical studies with DCA already provided evidence showing the effectiveness of DCA as a potent anticancer drug in several tumors. Interestingly, being a small molecule able to penetrate most tissues and readily crossing the blood-brain Barrier after oral administration [162], together with its low price make this compound a promising anticancer drug capable of being used in clinical settings. In fact, in 2010 an open label trial of oral DCA in five patients with recurrent glioblastoma, showed promising results in three subjects in terms of tumor biochemistry and progression [163]. Drug safety was limited initially by peripheral neuropathy that was reversible upon DCA dose reduction. Another phase I trial (NCT01111097) in adults with recurrent malignant brain tumors showed that oral DCA administration is safe, well-tolerated and feasible in these patients [157]. Moreover DCA therapy was associated with clinical and radiographic evidence of disease stabilization through the first 4 weeks of DCA administration. Biochemical studies performed in fresh samples prevenient from patient with glioblastoma treated with DCA showed that the drug depolarized the mitochondrial membrane potential, increased ROS, activated p53 and inhibited the expression of HIF-1 $\alpha$ and VEGF [164]. Despite these positive results, DCA has a plasma half-life of approximately $1 \mathrm{~h}$ in drug-naïve individuals, which could be increase several-fold with chronic administration, yet at a risk of serious side effects with higher doses [157].

A phase II clinical trial was designed to determine the safety, tolerability and response rate of DCA in patients with refractory metastatic breast and non-small cell lung cancers (NCT01029925), however, after the admission of the first seven patients, the study was closed based on safety concerns [165]. Moreover, a phase I clinical trial for the treatment of recurrent head and neck cancers (NCT01163487) is ongoing and multiple clinical trials are recruiting or undergoing to test DCA in combination with other therapies in several types of cancer (please see clinicaltrial.org for further details).

\section{Involvement of glucose metabolism in response to pharmacological therapy}




\subsection{Classical chemotherapy}

For several years, anticancer therapy was based on the higher capacity of tumor cell proliferation compared to normal cells. Therefore, most chemotherapeutic agents currently used in the clinical context target rapidly dividing cells. The main groups include: DNA alkylating agents, platinum-based agents, anti-neoplastic antibiotics, antimetabolites, anti-mitotic agents and topoisomerase inhibitors, which main target is DNA replication. Thus, this type of therapy does not distinguish between tumor and normal cells but instead between rapid and slowly proliferating cells, leading to important side effects at the level of highly proliferative tissues, including bone marrow, gastro-intestinal tract, hair follicles and gonads.

Tumor cells that initially may respond to chemotherapy, frequently develop resistance to a variety of drugs, leading to treatment failure. There are several mechanisms by which cancer cells become resistant to cancer chemotherapy, including higher capacity to repair DNA damage, production of nucleophilic substances (e.g. glutathione), target alteration, activation, and overexpression of efflux pumps. Additionally, and as a result of extensive studies to better understand the cell alterations behind drug resistance, the energetic metabolic switch appears as an important factor [166]. In fact, it is described that the hypoxic microenvironment [167], is one of the major factors involved in drug resistance and so the reactivation of a "normal metabolic state" could revert drug resistance and increase the efficacy of some chemotherapeutic agents already used in the clinic.

Based on the highly glycolytic phenotype, numerous mechanisms are behind tumor resistance to chemotherapy. Firstly, as mentioned before, the increase of glucose consumption will consequently lead to the production of high amounts of lactate [12]. In order to avoid deleterious intracellular acidity, tumor cells need to export lactate to the extracellular milieu, leading to an advantageous acidic microenvironment. In fact, it is attested that the alteration of the tumor microenvironment by the variation of the $\mathrm{pH}$ gradient between the extracellular environment and cell cytoplasm is behind the resistance to many cytotoxic drugs. For example, weakly basic chemotherapeutic drugs have their effect reduced in tumors, due to the more acidic extracellular $\mathrm{pH}$ of solid tumors, which impairs their uptake [168]. In addition, a higher glycolytic metabolism will also lead to higher production of NADPH, which will enable cells to maintain the levels of reduced forms of glutathione (GSH). This non-enzymatic antioxidant agent as been related to the capacity of tumor cells to counteract some of the effects of chemotherapeutic agents by maintaining their redox status [169]. All this evidence indicates a biochemical link between drug resistance and glycolytic metabolism, and, therefore the design of new therapeutic approaches combining chemotherapeutic drugs with glycolytic inhibitors will be of great value. In fact, some preclinical studies already demonstrated the potential of glycolytic inhibitors as an additional option for combination therapy. Studies involving the use of inhibitors of glycolytic targets in the response to classical chemotherapy are summarized below.

\subsubsection{Hexokinase II inhibitors}

Many studies explored the combination of hexokinase inhibitors with chemotherapy. The use 
of 2-DG significantly increased the effect of adriamycin (anti-neoplastic antibiotic) and paclitaxel (anti-mitotic agent) in mice with human osteosarcoma or non-small-cell lung cancer xenografts [170]. Also, Maschek and co-workers showed that adriamycin-resistant breast cancer cells have a 3-fold increase of glycolytic rates, which could be due to defective mitochondria. Another preclinical study with 2-DG also demonstrated to overcome tumor cell resistance to cisplatin [171]. The use of another HK II inhibitor, lonidamine, rescued the resistance phenotype of breast and glioblastoma cancer cells to adriamycin and nitrosurea (alkylating agent), respectively [172]. Importantly, these two inhibitors of HK II are already in clinical trials in combination with other agents in different solid tumors [173]. Regarding lonidamine, clinical studies showed that combination with different chemotherapeutic agents (cisplatin, platinum-based agent; epirubicin, anti-neoplastic antibiotic; vindesine, anti-mitotic agent) improved survival in patients with advanced lung cancer [174], ovarian cancer [175] and with advanced breast cancer, also showing reduction in the size of liver metastases [176]. Although there are no clinical studies on the efficacy of 3-BP as monotherapy, there is evidence showing that 3-BP can also overcome resistance to doxorubicin [177].

\subsubsection{Lactate dehydrogenase inhibitors}

Going downstream of the glycolytic pathway, there are also studies showing the involvement of LDHA in drug resistance. Zhou and coworkers showed that LDHA play a crucial role in palitaxel resistance in breast cancer cells. Moreover, treatment of breast cancer cells with the combination of palitaxel plus oxamate showed a synergistic effect on tumor cell death [178]. In addition, other studies showed that LDHA inhibition sensitizes chondrosarcoma cells to doxorubicin (antibiotic) [179] or resensitizes colon cancer cells to 5-fluorouracil (anti-metabolite) [180]. Interestingly, there are several clinical trials already complete or still recruiting, testing the combination of AT-101 with different standard chemotherapy in several tumors. (further details in: clinicaltrial.gov)

\subsubsection{Pyruvate dehydrogenase kinase inhibitors}

Beyond the promising effect of DCA as anticancer therapy, few studies have combined this drug with standard chemotherapeutic agents in an effort to overcome resistance. Preclinical studies have demonstrated that DCA increases the antitumor effects of several chemotherapeutic agents, for instance DCA sensitizes lung tumor cells to capecitabine (anti-metabolite) [181] and also to platinumbased drugs $[165,182]$ promoting apoptosis of these cells. Additionally, in gastric cancer, DCA is able to revert resistance to 5-fluorouracil induced by the hypoxic microenvironment. [183] Moreover, Kumar and co-workers showed that DCA chemosensitized Iymphoma cells to cisplatin, and this was due to modulation of glucose metabolism, followed by restoration of tumor microenvironment $\mathrm{pH}$ [184]. Interestingly, there is already an open-label trial of oral DCA in combination with cisplatin in patients with head and neck carcinoma.

\subsubsection{Lactate transport inhibitors}

As already mentioned, high tumor lactate levels are reported to correlate directly with resistance to different therapies, and thus lactate transporters appear as potential targets for 
sensitization of cancer cells to therapy. Indeed, our group demonstrated that inhibiting MCT1 with CHC exhibited anti-tumoral and anti-angiogenic activity in gliomas and, more importantly increased the effect of temozolomide [141]. In another study, we also showed that MCT1 and the chaperone CD147 are responsible for cisplatin resistance in bladder cancer [144].

Some explanations have been put forward for the success of the combination of anti-glycolytic agents with chemotherapy. For instance, cells treated with agents that cause DNA damage, such as cisplatin and alkylating agents, require high levels of ATP to rapidly repair these lesions, and so inhibiting ATP production using glycolytic inhibitors sensitizes tumor cells to these agents [185]. Moreover, inhibition of ATP production will also interfere with the effect of drugs that are substrates of p-glycoprotein effluxing pumps that require energy for their activity. Thus, with low ATP, the function of these pumps is compromised and drugs will no longer be exported outside the cells easily. In this line of evidence, combination of glycolytic inhibitors with anticancer agents should provide clinical benefit and maybe effectively kill cancer cells.

\subsection{Oncogene-targeted therapies}

The elucidation of deregulated kinase signaling pathways in cancer, including RTKs and their intracellular pathways (Figure 2) [186-189], along with the identification of kinases as targeted molecules, lead to a highly productive development of novel and effective antineoplastic drugs [190, 191]. Strategies include the development of selective components that can target the extracellular ligand-binding domain [monoclonal antibodies $(\mathrm{mAb})]$, the intracellular tyrosine kinase or the substrate-binding region [small tyrosine kinase inhibitors (TKi)] (Figure 2).

Although the concept of oncogene addiction has been observed in many preclinical models and has led to some initially impressive clinical results, similarly to conventional chemotherapy, the main challenge of targeted therapy is drug resistance [192-195]. There are some hypothesis trying to explain the acquired resistance to oncogene-targeted therapies [194, 195], yet the molecular mechanisms underlying this resistant phenotype is far from being understood. Thus, a better knowledge of cancer cell biology and their response and adaptation to drug treatment is fundamental and urgent for rationally designed combination schemes and multi-targeted therapies required to achieve longlasting effects [193, 194].

Recent reports have demonstrated that the metabolic rewiring of cancer cells can potentially drive resistance to oncogene-targeted therapies (summarized in Table 2). In this section we intend to give an overview of the actual knowledge on glucose metabolism alterations upon the use of targeted drugs, as well as the molecular mechanisms through which this glycolytic reprogramming can occur, and finally to discuss a way to overcome the resistance driven by the altered glucose consumption in cancer cells.

\subsubsection{KIT, PDGFRA and BCR-ABL inhibitors}


KIT and PDGFR belong to the type III subfamily of RTKs and due to the structural similarities of KIT and PDGFR kinase domains, the majority of TKi for KIT can also target PDGFR and vice-versa $[191,196]$. Imatinib is a KIT and PDGFRA inhibitor that was first clinically used in chronic myeloid leukemia (CML) harboring BCR-ABL kinase fusion and gained posterior approval for gastrointestinal stromal tumors (GIST). Imatinib became a paradigm in solid tumor treatment, reversing an untreatable disease into a tumor entity in which up to $85 \%$ of patients that receive the drug achieve disease control [197]. However, since imatinib treatment was one of the first successful approved molecular targeted therapies, it was also one of the first to whom therapy resistance was reported, mainly in CML [191].

At clinically relevant concentrations, imatinib strongly induces p53-dependent cell death [198], suppressing cytosolic glycolysis then increases the TCA cycle intermediates evoking a compensatory activation of mitochondrial function in CML [199-201]. In contrast, imatinib-resistant CML cells maintain highly glycolysis irrespective of the treatment [202], and maintenance of glucose uptake inhibited p53 activation [198], suggesting that increased glucose metabolism participates in imatinib resistance. In accordance, it was found that BCR-ABL positive cells express the high-affinity GLUT-1 glucose transporter and have increased glucose uptake [203-206]. Activation of the $\mathrm{PI} 3 \mathrm{~K} / \mathrm{AKT} / \mathrm{mTOR}$ pathway by BCR-ABL contributes to this high glycolytic activity, through a PI3Kdependent translocation of glucose transporters to the plasma membrane [199, 206-208]. Furthermore, it has been shown that enhanced expression of BCR-ABL in imatinib-resistant cells correlated with a non-hypoxic induction of HIF-1 $\alpha$ that was required for cells to enhance the rates of glycolysis but reduce glucose flux through both the TCA cycle and the oxidative arm of the PPP [201, 209, 210]. Additionally, mitochondrial dysfunction may also play a role in imatinib resistance via the production of mitochondrial ROS [201].

Due to the inherent resistance associated with imatinib treatment, novel BCR-ABL and KIT inhibitors have been developed, as is the case of multi-kinase targeted drugs dasatinib, sorafenib or axitinib, however they seem to share the same adaptations to glucose metabolism such as imatinib.

In chronic lymphocytic leukemia (CLL), it was shown that dasatinib induced glucose use, while reducing lactate production, suggesting that this tyrosine kinase inhibitor decreases aerobic glycolysis and shifts glucose use for OXPHOS [211]. In addition, dasatinib sensitive samples are more sensitive to both inhibition of OXPHOS (Metformin) and glycolysis (2-DG) than dasatinib resistant samples and that this difference might be associated with a higher capacity in this later subset of cases to adapt to energetic stress [211].

Sorafenib promotes an early perturbation of mitochondrial function in breast cancer cells, associated with a drop of intracellular ATP levels and increase of ROS generation, inducing the activation of AMP-activated protein kinase (AMPK) [212]. As a response to these alterations, AMPK enhanced glucose uptake by up-regulating the expression of GLUT-1, and increased lactate production [212].

Finally, Hudson et al. found that the resistant pancreatic adenocarcinoma cells to treatment with axitinib have a 2 -fold increase in ${ }^{14} \mathrm{C}-\mathrm{DG}$ uptake, followed by a translocation of GLUT-1 to the 
cell surface membrane, a 2-fold increase in glycolysis rates measured by the extracellular acidification rate (ECAR) and increased levels of MCT-4 protein expression and AKT phosphorylation [213].

Expectantly, considering the resistance that has been described for this class of inhibitors, it has also been shown that inhibition of glycolysis with 2-DG enhanced imatinib sensitivity in BCRABL-expressing CML cells with wild-type p53 [198], as the GLUT-1 inhibitor fasentin blocked sorafenib-induced glucose uptake and potentiated its cytotoxic activity breast cancer cell lines [212] or by blocking AKT activation it is possible to reverse the GLUT-1 translocation and restored the sensitivity of pancreatic cells to axitinib treatment [213].

\subsubsection{ErbB family Inhibitors}

The HER family (or ErBb) of receptors comprises the family I of RTKs that includes EGFR, HER2, HER3 and HER4 [186]. Anti-EGFR and HER2 therapies are the most widely used and explored due to the high number of tumors harboring alterations in these two receptors [194].

In relation to glucose metabolism, it was recently shown that EGFR signaling up-regulate aerobic glycolysis in EGFR-mutated lung adenocarcinoma cells, through the regulation of GLUT3 and pentose phosphate pathways [214]. Besides, it was reported that hypoxia drives expression of pyruvate dehydrogenase kinase (PDK1) and EGFR along with the HIF-1 $\alpha$, initiating a feed-forward loop that can sustain malignant progression in human glioblastoma cells [215]. In accordance, inhibition of EGFR signaling with erlotinib or gefitinib abrogated the Warburg effect by inhibiting multiple steps including MYC-driven transcription, phosphorylation of PKM2 and hexokinase activity to regulate glycolysis in EGFR mutant lung adenocarcinoma [214, 216].

$E G F R$ wild-type tumors are usually treated with the monoclonal antibody cetuximab. It has been shown that cetuximab treatment downregulates glycolysis through HIF-1 $\alpha$ inhibition, which is dependent on effective inhibition of PI3K/AKT pathway in non-small-cell lung carcinoma (NSCLC) [217, 218], and in LDHA downregulation in head and neck squamous cell carcinoma (HNSCC) cells [219]. In contrast, it was also described that colorectal cancer models with acquired resistance to cetuximab have a significantly higher production of lactate [220], and in the HNSCC models the resistant cells overexpressed HIF-1 $\alpha$ and are highly glycolytic [219]. Moreover, overexpression of HIF-1 $\alpha$ conferred cellular resistance to cetuximab-induced apoptosis in sensitive lung adenocarcinoma cells $[217,218]$.

Komurov and colleagues also found that lapatinib (EGFR and HER2 inhibitor) induction of toxicity in HER2-positive breast cancer cells is associated with glucose deprivation, and that prolonged lapatinib treatment can lead to acquired resistance that is characterized by increased expression of networks involved in glucose deprivation or hypoglycemic response [221].

Thus, there is compiling amount of data that provide evidence linking the ErbB inhibitors response to the regulation of energetic metabolism in ErbB-dependent tumors. Therefore, combination therapies of ErbB inhibitors and drugs that block glycolysis pathway would be expected to be much more effective circumvent acquired resistance. In fact, Kim et al. showed that targeting of glycolysis with 2-DG was an effective therapeutic option to overcome the limited efficacy of afatinib (irreversible inhibitor of EGFR and HER2) in lung adenocarcinoma cells with EGFR resistant mutation [222]. 
Moreover, inhibiting LDHA activity with oxamate enhanced the response of HNSCC cells to cetuximab [219].

\subsubsection{BRAF inhibitors}

The development of therapies targeting BRAF in melanoma is a clear example of successful targeting of an oncogene for the treatment of cancer [223]. Catalytic BRAF inhibitors (such as vemurafenib), have profound efficacy in tumors carrying activating mutations, particularly to the V600 amino acid substitution [223]. Importantly, activating $B R A F$ mutations, have been associated with increased glycolytic activity and cell surface GLUT1 expression in colorectal and thyroid cancer cells $[21,224]$, indicating that glucose metabolism could be important for BRAF-driven tumorigenesis.

In melanoma cell lines it was shown that BRAF inhibition with vemurafenib potently suppressed glycolysis via suppression of hexokinase II and GLUT1/3 expression [225]. However, it was also found that glucose metabolism is restored upon development of vemurafenib resistance due to alterations in a network of transcriptional regulators of glycolysis, composed of HIF-1 $\alpha$, MYC, and MONDOA induced by BRAF inhibitor treatment $[225,226]$. Notably, DCA potentiated the antitumor effects of the vemurafenib in resistant $B R A F$ V600E-mutant melanoma cells [225, 227].

Other studies have reported that mitochondrial respiration and oxidative phosphorylation are decreased in metastatic melanomas, even under normoxic conditions due to the persistence of a high nuclear expression of HIF-1 $\alpha$ [227]. Thus, acquired resistance to BRAF inhibitor could be in part attributed to increased mitochondrial biogenesis and enhanced stress tolerance in melanoma [228], that are sustained by autophagy, a survival mechanism exploited by tumor cells to meet their elevated metabolic demands and to tolerate stress [228]. Therefore, it has been suggested that combined inhibition of autophagy and BRAF may overcome BRAF inhibitor resistance [228].

\subsubsection{VEGF/anti-angiogenic inhibitors}

The anti-tumor activity of angiogenic inhibitors is often limited by the development of resistance to these drugs [229]. In vivo studies suggest that anti-VEGF therapy, such as bevacizumab, can alter the tumor's phenotype, by generating a hypoxic-stressed tumor microenvironment inducing invasion and tumoral aggressiveness [230].

In glioblastoma xenografts, bevacizumab decreased microvessel-density and increased intratumor-hypoxia, but did not induce apoptosis [231]. Moreover, bevacizumab alone caused a significant increase of HIF-1 $\alpha$-dependent gene expression in glioblastoma tissues [231]. Additionally, microarray analysis of resistant glioblastoma xenografts tumors revealed coordinated changes at the level of metabolic genes, in particular, uncoupling glycolysis from oxidative phosphorylation [232, 233], which has been confirmed by increased expression of glycolytic enzymes including PDK in the treated tumors [233]. Upregulation of HIF-1 $\alpha$ appears to be also significant mechanism of resistance to antiangiogenic therapies in neuroblastoma [234].

In colorectal in vivo models, metabolic assays, revealed a significantly impaired mitochondrial function and hyperactive glycolysis, which were concomitant with the upregulation of HIF-1 $\alpha$ in bevacizumab treated tumors [235]. In accordance, in colorectal cancer cell lines, bevacizumab caused a 
significant increase in cellular senescence associated with upregulation of p16 [236]. Similarly, hypoxia-mediated autophagy promotes tumor cell survival in glioblastomas resistant to bevacizumab [237]. Importantly, glycogen metabolism is upregulated in tumors in vivo and in cancer cells in vitro in response to hypoxia, inducing autophagy and senescence mechanisms in glioblastoma [238]. Thus, glycogen metabolism seems to be a key pathway necessary for optimal glucose utilization in hypoxicstressed tumor microenvironment induced by anti-angiogenic therapies [238], representing a targetable mechanism to overcome resistance to those therapies.

Actually, it is already known that suppressing HIF-1 $\alpha$ with low-dose topotecan potentiates the effects of the antiangiogenic drugs in mouse models of neuroblastoma and glioblastoma [231, 234]. In colorectal cancer xenograft models, treatment of bevacizumab-resistant cells with the glycolysis inhibitor 3-BP resulted in smaller tumor volume and longer survival [235], while bevacizumab and DCA together dramatically blocked tumor growth compared to either drug alone [232], suggesting that glycolysis blockade may also potentiate the therapeutic effect of anti-angiogenic treatment $[232,233$, 235].

As a summary of this part, in general, HIF- $1 \alpha$ is pointed as the crucial player in the modulation of glucose metabolism, inducing cellular survival mechanisms such as glycogen storage, senescence and autophagy (summarized in Table 2), which culminates in tumor resistance to molecular targeted therapies.

It is apparent from experimental studies and also clinical experience with molecular targeted agents that cancers often "escape" their "oncogene addicted" state, which can be mainly attributed to deregulation of signaling pathways that can sometimes alleviate or bypass the "addiction" to another pathway, causing relapse of the tumor even after pronounced initial responses [192-195]. Also, it is of general knowledge that activation of some RTKs, mainly EGFR and VEGF signaling, may stimulate rise in HIF-1 $\alpha$ in a cell type-specific manner [239-241]. Thus, is not clear whether the HIF-1 $\alpha$-induced glycolysis is the cause or just a consequence of development of therapy resistance, but it seems clear that HIF-1 $\alpha$ up-regulation could be a consequence of a signaling bypass in the resistant tumors, as cited above. The work of Nilsson et al, support at least in part this hypothesis, since they found that multiple RTKs may regulate the HIF-1 $\alpha$ axis in normoxia and hypoxia and suggest that multi-kinase inhibitors (such as sunitinib, in contrast to imatinib) may exert anti-angiogenic effects not only by direct effects on endothelial cells, but also by blocking compensatory hypoxia- and ligand-induced changes in HIF$1 \alpha$ and HIF-2 $\alpha$ in neuroblastoma cells [242].

Actually, in preclinical models, the best strategies tested to overcome glycolysis induction of therapy resistance included HIF-1 $\alpha$ inhibition, AKT phosphorylation blockage, glucose uptake impairment, LDHA and PDK inhibition, as well as autophagy reduction. In addition to glycolysis inhibition to revert resistance, as protein kinase inhibitors exert their action by binding to the ATP binding site on the targeted kinases, it has been also hypothesized that a decrease in ATP levels in neoplastic cells could reduce the competition for the same enzymatic site, thus increasing the efficacy of kinase inhibitors [243]. 


\section{General Conclusions}

The development of treatments that target tumor metabolism is receiving renewed attention, with several potential drugs currently in clinical trials. As discussed above, metabolic reprogramming renders cancer cells dependent on specific metabolic pathways that could be exploited in cancer therapy. Nevertheless, the rationale for targeting tumor glycolysis should be clear and precise and the success of selecting an anti-cancer therapeutic strategy should be based on the ability to choose a very specific agent for the molecular target. However, the success of such agents may be complicated by the high plasticity of the metabolic network that can induce compensatory biosynthetic routes [244], such as increased glutaminolysis or oxidative phosphorylation for energy production [245]. Thus, a new line of attacking cancer could be the combination of anti-glycolytic agents with other therapies. In fact, combination of glycolytic inhibitors with chemotherapeutic drugs, has already revealed to be a promising strategy to overcome drug resistance.

Moreover, glycolytic phenotype has a significant role in cancer chemoresistance, by acidification of the extracellular milieu, and thus inhibition of glycolytic metabolism could be a good strategy to sensitize tumor cells and to improve the outcome of chemotherapy. In fact, preclinical studies have been demonstrating the success of combining classical chemotherapy with glycolytic inhibitors. Additionally, cells with higher basal glycolytic rates are potentially more resistant to molecular targeted therapies. In this line of evidence, several studies suggest that a tumor is more responsive to a kinase inhibitor if it has a more inhibitory effect on glycolysis blockage, since glycolysis gives an important growth advantage to most transformed cells. Further, continuous treatment of tumors with kinase inhibitors elicits a restoration of the glucose metabolism rates, leading to acquired resistance. Thus, the upregulation of glucose metabolism as a compensatory response to chemotherapy elicits the potential of using anti-glycolytic drugs to overcome resistance.

In conclusion, it appears wise to assess tumour glucose uptake or glycolytic-related protein activity in the patient clinical management to predict therapy response, and importantly, to use therapeutic strategies to block abnormal glucose metabolism as suitable approaches to overcome or prevent therapy resistance to oncogene-targeted therapy.

\section{References}

1. Hanahan D, Weinberg RA: Hallmarks of cancer: the next generation. Cell 2011, 144(5):646674.

2. Warburg O: On the origin of cancer cells. Science 1956, 123(3191):309-314.

3. Gatenby RA, Gillies RJ: Why do cancers have high aerobic glycolysis? Nature reviews Cancer 2004, 4(11):891-899.

4. Pelicano H, Martin DS, Xu RH, Huang P: Glycolysis inhibition for anticancer treatment. Oncogene 2006, 25(34):4633-4646.

5. Chen Z, Lu W, Garcia-Prieto C, Huang P: The Warburg effect and its cancer therapeutic implications. Journal of bioenergetics and biomembranes 2007, 39(3):267-274. 
6. Cuezva JM, Krajewska M, de Heredia ML, Krajewski S, Santamaria G, Kim H, Zapata JM, Marusawa $\mathrm{H}$, Chamorro M, Reed JC: The bioenergetic signature of cancer: a marker of tumor progression. Cancer research 2002, 62(22):6674-6681.

7. Isidoro A, Martinez M, Fernandez PL, Ortega AD, Santamaria G, Chamorro M, Reed JC, Cuezva JM: Alteration of the bioenergetic phenotype of mitochondria is a hallmark of breast, gastric, lung and oesophageal cancer. The Biochemical journal 2004, 378(Pt 1):17-20.

8. Matoba S, Kang JG, Patino WD, Wragg A, Boehm M, Gavrilova O, Hurley PJ, Bunz F, Hwang PM: p53 regulates mitochondrial respiration. Science 2006, 312(5780):1650-1653.

9. Vander Heiden MG, Plas DR, Rathmell JC, Fox CJ, Harris MH, Thompson CB: Growth factors can influence cell growth and survival through effects on glucose metabolism. Molecular and cellular biology 2001, 21(17):5899-5912.

10. Ran C, Liu H, Hitoshi Y, Israel MA: Proliferation-independent control of tumor glycolysis by PDGFR-mediated AKT activation. Cancer research 2013, 73(6):1831-1843.

11. Bui T, Thompson CB: Cancer's sweet tooth. Cancer cell 2006, 9(6):419-420.

12. Deberardinis RJ, Sayed N, Ditsworth D, Thompson CB: Brick by brick: metabolism and tumor cell growth. Current opinion in genetics \& development 2008, 18(1):54-61.

13. Szablewski L: Expression of glucose transporters in cancers. Biochim Biophys Acta 2013, 1835(2):164-169.

14. Van den Abbeele AD, Badawi RD: Use of positron emission tomography in oncology and its potential role to assess response to imatinib mesylate therapy in gastrointestinal stromal tumors (GISTs). European journal of cancer (Oxford, England : 1990) 2002, 38 Suppl 5:S6065.

15. Hughes B, Yip D, Goldstein D, Waring P, Beshay V, Chong G: Cerebral relapse of metastatic gastrointestinal stromal tumor during treatment with imatinib mesylate: case report. $B M C$ cancer 2004, 4:74.

16. Breccia M, Muscaritoli M, Aversa Z, Mandelli F, Alimena G: Imatinib mesylate may improve fasting blood glucose in diabetic $\mathrm{Ph}+$ chronic myelogenous leukemia patients responsive to treatment. Journal of clinical oncology : official journal of the American Society of Clinical Oncology 2004, 22(22):4653-4655.

17. Breccia M, Muscaritoli M, Cannella L, Stefanizzi C, Frustaci A, Alimena G: Fasting glucose improvement under dasatinib treatment in an accelerated phase chronic myeloid leukemia patient unresponsive to imatinib and nilotinib. Leukemia research 2008, 32(10):1626-1628.

18. McArthur GA, Puzanov I, Amaravadi R, Ribas A, Chapman P, Kim KB, Sosman JA, Lee RJ, Nolop K, Flaherty KT et al: Marked, homogeneous, and early [18F]fluorodeoxyglucose-positron emission tomography responses to vemurafenib in BRAF-mutant advanced melanoma. Journal of clinical oncology : official journal of the American Society of Clinical Oncology 2012, 30(14):1628-1634.

19. Baudy AR, Dogan T, Flores-Mercado JE, Hoeflich KP, Su F, van Bruggen N, Williams SP: FDGPET is a good biomarker of both early response and acquired resistance in BRAFV600 mutant melanomas treated with vemurafenib and the MEK inhibitor GDC-0973. EJNMMI research 2012, 2(1):22.

20. Grimpen F, Yip D, McArthur G, Waring P, Goldstein D, Loughrey M, Beshay V, Chong G: Resistance to imatinib, low-grade FDG-avidity on PET, and acquired KIT exon 17 mutation in gastrointestinal stromal tumour. The Lancet Oncology 2005, 6(9):724-727.

21. Yun J, Rago C, Cheong I, Pagliarini R, Angenendt P, Rajagopalan H, Schmidt K, Willson JK, Markowitz $S$, Zhou $S$ et al: Glucose deprivation contributes to the development of KRAS pathway mutations in tumor cells. Science (New York, NY) 2009, 325(5947):1555-1559.

22. Bhattacharya B, Low SH, Soh C, Kamal Mustapa N, Beloueche-Babari M, Koh KX, Loh J, Soong $\mathrm{R}$ : Increased drug resistance is associated with reduced glucose levels and an enhanced glycolysis phenotype. British journal of pharmacology 2014, 171(13):3255-3267.

23. Elstrom RL, Bauer DE, Buzzai M, Karnauskas R, Harris MH, Plas DR, Zhuang H, Cinalli RM, Alavi A, Rudin CM et al: Akt stimulates aerobic glycolysis in cancer cells. Cancer research 2004, 64(11):3892-3899.

24. Luo Y, Yang C, Ye M, Jin C, Abbruzzese JL, Lee MH, Yeung SC, McKeehan WL: Deficiency of metabolic regulator FGFR4 delays breast cancer progression through systemic and microenvironmental metabolic alterations. Cancer \& metabolism 2013, 1(1):21. 
25. Shimura T, Noma N, Sano Y, Ochiai Y, Oikawa T, Fukumoto M, Kunugita N: AKT-mediated enhanced aerobic glycolysis causes acquired radioresistance by human tumor cells. Radiotherapy and oncology : journal of the European Society for Therapeutic Radiology and Oncology 2014.

26. Park SY, Kim EJ, Shin HK, Kwon DY, Kim MS, Surh YJ, Park JH: Induction of apoptosis in HT-29 colon cancer cells by phloretin. Journal of medicinal food 2007, 10(4):581-586.

27. Wu CH, Ho YS, Tsai CY, Wang YJ, Tseng H, Wei PL, Lee $\mathrm{CH}$, Liu RS, Lin SY: In vitro and in vivo study of phloretin-induced apoptosis in human liver cancer cells involving inhibition of type II glucose transporter. International journal of cancer Journal international du cancer 2009, 124(9):2210-2219.

28. Kobori M, Iwashita K, Shinmoto H, Tsushida T: Phloretin-induced apoptosis in B16 melanoma 4A5 cells and HL60 human leukemia cells. Bioscience, biotechnology, and biochemistry 1999, 63(4):719-725.

29. Kobori M, Shinmoto H, Tsushida T, Shinohara K: Phloretin-induced apoptosis in B16 melanoma 4A5 cells by inhibition of glucose transmembrane transport. Cancer letters 1997, 119(2):207-212.

30. Nelson JA, Falk RE: The efficacy of phloridzin and phloretin on tumor cell growth. Anticancer research 1993, 13(6A):2287-2292.

31. Pajor AM, Randolph KM, Kerner SA, Smith CD: Inhibitor binding in the human renal low- and high-affinity $\mathrm{Na}+$ /glucose cotransporters. The Journal of pharmacology and experimental therapeutics 2008, 324(3):985-991.

32. Cao X, Fang L, Gibbs S, Huang Y, Dai Z, Wen P, Zheng X, Sadee W, Sun D: Glucose uptake inhibitor sensitizes cancer cells to daunorubicin and overcomes drug resistance in hypoxia. Cancer chemotherapy and pharmacology 2007, 59(4):495-505.

33. Yang KC, Tsai CY, Wang YJ, Wei PL, Lee CH, Chen JH, Wu CH, Ho YS: Apple polyphenol phloretin potentiates the anticancer actions of paclitaxel through induction of apoptosis in human hep G2 cells. Molecular carcinogenesis 2009, 48(5):420-431.

34. Zhu SP, Liu G, Wu XT, Chen FX, Liu JQ, Zhou ZH, Zhang JF, Fei SJ: The effect of phloretin on human gammadelta $T$ cells killing colon cancer $\mathbf{S W}-1116$ cells. International immunopharmacology 2013, 15(1):6-14.

35. Zhan T, Digel M, Kuch EM, Stremmel W, Fullekrug J: Silybin and dehydrosilybin decrease glucose uptake by inhibiting GLUT proteins. Journal of cellular biochemistry 2011, 112(3):849-859.

36. Deep G, Agarwal R: Antimetastatic efficacy of silibinin: molecular mechanisms and therapeutic potential against cancer. Cancer metastasis reviews 2010, 29(3):447-463.

37. Flaig TW, Glode M, Gustafson D, van Bokhoven A, Tao Y, Wilson S, Su LJ, Li Y, Harrison G, Agarwal R et al: A study of high-dose oral silybin-phytosome followed by prostatectomy in patients with localized prostate cancer. Prostate 2010, 70(8):848-855.

38. Flaig TW, Gustafson DL, Su LJ, Zirrolli JA, Crighton F, Harrison GS, Pierson AS, Agarwal R, Glode LM: A phase I and pharmacokinetic study of silybin-phytosome in prostate cancer patients. Invest New Drugs 2007, 25(2):139-146.

39. Siegel AB, Narayan R, Rodriguez R, Goyal A, Jacobson JS, Kelly K, Ladas E, Lunghofer PJ, Hansen RJ, Gustafson DL et al: A phase I dose-finding study of silybin phosphatidylcholine (milk thistle) in patients with advanced hepatocellular carcinoma. Integrative cancer therapies 2014, 13(1):46-53.

40. Sadava $D$, Kane SE: Silibinin reverses drug resistance in human small-cell lung carcinoma cells. Cancer letters 2013, 339(1):102-106.

41. Chang HR, Chen PN, Yang SF, Sun YS, Wu SW, Hung TW, Lian JD, Chu SC, Hsieh YS: Silibinin inhibits the invasion and migration of renal carcinoma 786-0 cells in vitro, inhibits the growth of xenografts in vivo and enhances chemosensitivity to 5-fluorouracil and paclitaxel. Molecular carcinogenesis 2011, 50(10):811-823.

42. Rho JK, Choi YJ, Jeon BS, Choi SJ, Cheon GJ, Woo SK, Kim HR, Kim CH, Choi CM, Lee JC: Combined treatment with silibinin and epidermal growth factor receptor tyrosine kinase inhibitors overcomes drug resistance caused by T790M mutation. Molecular cancer therapeutics 2010, 9(12):3233-3243. 
43. Noori-Daloii MR, Saffari M, Raoofian R, Yekaninejad M, Dinehkabodi OS, Noori-Daloii AR: The multidrug resistance pumps are inhibited by silibinin and apoptosis induced in $\mathrm{K} 562$ and KCL22 leukemia cell lines. Leukemia research 2014, 38(5):575-580.

44. Dhanalakshmi S, Agarwal P, Glode LM, Agarwal R: Silibinin sensitizes human prostate carcinoma DU145 cells to cisplatin- and carboplatin-induced growth inhibition and apoptotic death. International journal of cancer Journal international du cancer 2003, 106(5):699-705.

45. Tyagi AK, Agarwal C, Chan DC, Agarwal R: Synergistic anti-cancer effects of silibinin with conventional cytotoxic agents doxorubicin, cisplatin and carboplatin against human breast carcinoma MCF-7 and MDA-MB468 cells. Oncology reports 2004, 11(2):493-499.

46. Flaig TW, Su LJ, Harrison G, Agarwal R, Glode LM: Silibinin synergizes with mitoxantrone to inhibit cell growth and induce apoptosis in human prostate cancer cells. International journal of cancer Journal international du cancer 2007, 120(9):2028-2033.

47. Cufi S, Bonavia R, Vazquez-Martin A, Oliveras-Ferraros C, Corominas-Faja B, Cuyas E, MartinCastillo B, Barrajon-Catalan E, Visa J, Segura-Carretero A et al: Silibinin suppresses EMTdriven erlotinib resistance by reversing the high miR-21/low miR-200c signature in vivo. Scientific reports 2013, 3:2459.

48. Hussain SA, Marouf BH: Silibinin improves the cytotoxicity of methotrexate in chemo resistant human rhabdomyosarcoma cell lines. Saudi medical journal 2013, 34(11):11451150.

49. Nasiri M, Zarghami N, Koshki KN, Mollazadeh M, Moghaddam MP, Yamchi MR, Esfahlan RJ, Barkhordari A, Alibakhshi A: Curcumin and silibinin inhibit telomerase expression in T47D human breast cancer cells. Asian Pacific journal of cancer prevention : APJCP 2013, 14(6):3449-3453.

50. Ebrahimnezhad Z, Zarghami N, Keyhani M, Amirsaadat S, Akbarzadeh A, Rahmati M, Mohammad Taheri Z, Nejati-Koshki K: Inhibition of hTERT Gene Expression by SilibininLoaded PLGA-PEG-Fe304 in T47D Breast Cancer Cell Line. Biolmpacts : BI 2013, 3(2):67-74.

51. Thelen $\mathrm{P}$, Wuttke $\mathrm{W}$, Jarry $\mathrm{H}, \mathrm{Grzmil} \mathrm{M}$, Ringert $\mathrm{RH}$ : Inhibition of telomerase activity and secretion of prostate specific antigen by silibinin in prostate cancer cells. The Journal of urology 2004, 171(5):1934-1938.

52. Zhang S, Yang Y, Liang Z, Duan W, Yang J, Yan J, Wang N, Feng W, Ding M, Nie Y et al: Silybinmediated inhibition of Notch signaling exerts antitumor activity in human hepatocellular carcinoma cells. PloS one 2013, 8(12):e83699.

53. Kim TH, Woo JS, Kim YK, Kim KH: Silibinin induces cell death through reactive oxygen species-dependent downregulation of notch-1/ERK/Akt signaling in human breast cancer cells. The Journal of pharmacology and experimental therapeutics 2014, 349(2):268-278.

54. Yousefi M, Ghaffari SH, Zekri A, Hassani S, Alimoghaddam K, Ghavamzadeh A: Silibinin induces apoptosis and inhibits proliferation of estrogen receptor (ER)-negative breast carcinoma cells through suppression of nuclear factor kappa B activation. Archives of Iranian medicine 2014, 17(5):366-371.

55. Velmurugan B, Gangar SC, Kaur M, Tyagi A, Deep G, Agarwal R: Silibinin exerts sustained growth suppressive effect against human colon carcinoma SW480 xenograft by targeting multiple signaling molecules. Pharmaceutical research 2010, 27(10):2085-2097.

56. Chan DA, Sutphin PD, Nguyen P, Turcotte S, Lai EW, Banh A, Reynolds GE, Chi JT, Wu J, Solow-Cordero DE et al: Targeting GLUT1 and the Warburg effect in renal cell carcinoma by chemical synthetic lethality. Science translational medicine 2011, 3(94):94ra70.

57. Boheler KR, Bhattacharya S, Kropp EM, Chuppa S, Riordon DR, Bausch-Fluck D, Burridge PW, Wu JC, Wersto RP, Chan GC et al: A human pluripotent stem cell surface $\mathbf{N}$-glycoproteome resource reveals markers, extracellular epitopes, and drug targets. Stem cell reports 2014, 3(1):185-203.

58. Adams DJ, Ito D, Rees MG, Seashore-Ludlow B, Puyang X, Ramos AH, Cheah JH, Clemons PA, Warmuth M, Zhu P et al: NAMPT Is the Cellular Target of STF-31-Like Small-Molecule Probes. ACS chemical biology 2014.

59. Liu Y, Cao Y, Zhang W, Bergmeier S, Qian Y, Akbar H, Colvin R, Ding J, Tong L, Wu S et al: A small-molecule inhibitor of glucose transporter 1 downregulates glycolysis, induces cellcycle arrest, and inhibits cancer cell growth in vitro and in vivo. Molecular cancer therapeutics 2012, 11(8):1672-1682. 
60. Murata H, Hruz PW, Mueckler M: The mechanism of insulin resistance caused by HIV protease inhibitor therapy. The Journal of biological chemistry 2000, 275(27):20251-20254.

61. Vyas AK, Koster JC, Tzekov A, Hruz PW: Effects of the HIV protease inhibitor ritonavir on GLUT4 knock-out mice. The Journal of biological chemistry 2010, 285(47):36395-36400.

62. McBrayer SK, Cheng JC, Singhal S, Krett NL, Rosen ST, Shanmugam M: Multiple myeloma exhibits novel dependence on GLUT4, GLUT8, and GLUT11: implications for glucose transporter-directed therapy. Blood 2012, 119(20):4686-4697.

63. Le Calve B, Rynkowski M, Le Mercier M, Bruyere C, Lonez C, Gras T, Haibe-Kains B, Bontempi $G$, Decaestecker $C$, Ruysschaert JM et al: Long-term in vitro treatment of human glioblastoma cells with temozolomide increases resistance in vivo through up-regulation of GLUT transporter and aldo-keto reductase enzyme AKR1C expression. Neoplasia 2010, 12(9):727-739.

64. Krasnov GS, Dmitriev AA, Lakunina VA, Kirpiy AA, Kudryavtseva AV: Targeting VDAC-bound hexokinase II: a promising approach for concomitant anti-cancer therapy. Expert opinion on therapeutic targets 2013, 17(10):1221-1233.

65. Mathupala SP, Ko YH, Pedersen PL: Hexokinase-2 bound to mitochondria: cancer's stygian link to the "Warburg Effect" and a pivotal target for effective therapy. Seminars in cancer biology 2009, 19(1):17-24.

66. Vander Heiden MG: Targeting cancer metabolism: a therapeutic window opens. Nature reviews Drug discovery 2011, 10(9):671-684.

67. El Mjiyad N, Caro-Maldonado A, Ramirez-Peinado S, Munoz-Pinedo C: Sugar-free approaches to cancer cell killing. Oncogene 2011, 30(3):253-264.

68. Kuntz S, Mazerbourg S, Boisbrun M, Cerella C, Diederich M, Grillier-Vuissoz I, Flament S: Energy restriction mimetic agents to target cancer cells: Comparison between 2deoxyglucose and thiazolidinediones. Biochemical pharmacology 2014.

69. Butler EB, Zhao Y, Munoz-Pinedo C, Lu J, Tan M: Stalling the engine of resistance: targeting cancer metabolism to overcome therapeutic resistance. Cancer research 2013, 73(9):27092717.

70. Landau BR, Laszlo J, Stengle J, Burk D: Certain metabolic and pharmacologic effects in cancer patients given infusions of 2-deoxy-D-glucose. Journal of the National Cancer Institute 1958, 21(3):485-494.

71. Dwarakanath BS, Singh D, Banerji AK, Sarin R, Venkataramana NK, Jalali R, Vishwanath PN, Mohanti BK, Tripathi RP, Kalia VK et al: Clinical studies for improving radiotherapy with 2deoxy-D-glucose: present status and future prospects. Journal of cancer research and therapeutics 2009, 5 Suppl 1:S21-26.

72. Galluzzi L, Kepp O, Vander Heiden MG, Kroemer G: Metabolic targets for cancer therapy. Nature reviews Drug discovery 2013, 12(11):829-846.

73. Raez LE, Papadopoulos K, Ricart AD, Chiorean EG, Dipaola RS, Stein MN, Rocha Lima CM, Schlesselman JJ, Tolba K, Langmuir VK et al: A phase I dose-escalation trial of 2-deoxy-Dglucose alone or combined with docetaxel in patients with advanced solid tumors. Cancer chemotherapy and pharmacology 2013, 71(2):523-530.

74. Stein M, Lin H, Jeyamohan C, Dvorzhinski D, Gounder M, Bray K, Eddy S, Goodin S, White E, Dipaola RS: Targeting tumor metabolism with 2-deoxyglucose in patients with castrateresistant prostate cancer and advanced malignancies. Prostate 2010, 70(13):1388-1394.

75. Corsi G, Palazzo G: 1-Halobenzyl-1H-indazole-3-carboxylic acids. A new class of antispermatogenic agents. Journal of medicinal chemistry 1976, 19(6):778-783.

76. Floridi A, Paggi MG, D'Atri S, De Martino C, Marcante ML, Silvestrini B, Caputo A: Effect of lonidamine on the energy metabolism of Ehrlich ascites tumor cells. Cancer research 1981, 41(11 Pt 1):4661-4666.

77. Di CS, Ferretti G, Papaldo P, Carlini P, Fabi A, Cognetti F: Lonidamine: efficacy and safety in clinical trials for the treatment of solid tumors. Drugs Today (Barc) 2003, 39(3):157-174.

78. Calvino E, Estan MC, Simon GP, Sancho P, Boyano-Adanez Mdel C, de Blas E, Breard J, Aller P: Increased apoptotic efficacy of lonidamine plus arsenic trioxide combination in human leukemia cells. Reactive oxygen species generation and defensive protein kinase (MEK/ERK, Akt/mTOR) modulation. Biochemical pharmacology 2011, 82(11):1619-1629.

79. Lena A, Rechichi M, Salvetti A, Bartoli B, Vecchio D, Scarcelli V, Amoroso R, Benvenuti L, Gagliardi R, Gremigni $V$ et al: Drugs targeting the mitochondrial pore act as cytotoxic and 
cytostatic agents in temozolomide-resistant glioma cells. Journal of translational medicine 2009, 7:13.

80. Ricotti L, Tesei A, De Paola F, Milandri C, Amadori D, Frassineti GL, Ulivi P, Zoli W: Potentiation of antiproliferative drug activity by lonidamine in hepatocellular carcinoma cells. Journal of chemotherapy 2003, 15(5):480-487.

81. Teicher BA, Herman TS, Holden SA, Epelbaum R, Liu SD, Frei E, 3rd: Lonidamine as a modulator of alkylating agent activity in vitro and in vivo. Cancer research 1991, 51(3):780784.

82. Teicher BA, Holden SA, Herman TS, Frei E, 3rd: Modulation of alkylating agents by lonidamine in vivo. Semin Oncol 1991, 18(2 Suppl 4):7-10.

83. Tanaka J, Teicher BA, Herman TS, Holden SA, Dezube B, Frei E, 3rd: Etoposide with lonidamine or pentoxifylline as modulators of alkylating agent activity in vivo. International journal of cancer Journal international du cancer 1991, 48(4):631-637.

84. Fanciulli M, Bruno T, Giovannelli A, Gentile FP, Di Padova M, Rubiu O, Floridi A: Energy metabolism of human LoVo colon carcinoma cells: correlation to drug resistance and influence of lonidamine. Clinical cancer research : an official journal of the American Association for Cancer Research 2000, 6(4):1590-1597.

85. Li YC, Fung KP, Kwok TT, Lee CY, Suen YK, Kong SK: Mitochondrial targeting drug lonidamine triggered apoptosis in doxorubicin-resistant HepG2 cells. Life sciences 2002, 71(23):27292740.

86. Papaldo P, Lopez M, Cortesi E, Cammilluzzi E, Antimi M, Terzoli E, Lepidini G, Vici P, Barone C, Ferretti $\mathrm{G}$ et al: Addition of either lonidamine or granulocyte colony-stimulating factor does not improve survival in early breast cancer patients treated with high-dose epirubicin and cyclophosphamide. Journal of clinical oncology : official journal of the American Society of Clinical Oncology 2003, 21(18):3462-3468.

87. Berruti A, Bitossi R, Gorzegno G, Bottini A, Alquati P, De Matteis A, Nuzzo F, Giardina G, Danese $S$, De Lena $M$ et al: Time to progression in metastatic breast cancer patients treated with epirubicin is not improved by the addition of either cisplatin or lonidamine: final results of a phase III study with a factorial design. Journal of clinical oncology : official journal of the American Society of Clinical Oncology 2002, 20(20):4150-4159.

88. Oudard S, Carpentier A, Banu E, Fauchon F, Celerier D, Poupon MF, Dutrillaux B, Andrieu JM, Delattre JY: Phase II study of lonidamine and diazepam in the treatment of recurrent glioblastoma multiforme. Journal of neuro-oncology 2003, 63(1):81-86.

89. De Lena M, Lorusso V, Latorre A, Fanizza G, Gargano G, Caporusso L, Guida M, Catino A, Crucitta E, Sambiasi D et al: Paclitaxel, cisplatin and lonidamine in advanced ovarian cancer. A phase II study. European journal of cancer 2001, 37(3):364-368.

90. Porporato PE, Dhup S, Dadhich RK, Copetti T, Sonveaux P: Anticancer targets in the glycolytic metabolism of tumors: a comprehensive review. Front Pharmacol 2011, 2:49.

91. Del Bufalo D, Trisciuoglio D, Scarsella M, D'Amati G, Candiloro A, lervolino A, Leonetti C, Zupi $\mathrm{G}$ : Lonidamine causes inhibition of angiogenesis-related endothelial cell functions. Neoplasia 2004, 6(5):513-522.

92. Milane L, Duan Z, Amiji M: Therapeutic efficacy and safety of paclitaxel/lonidamine loaded EGFR-targeted nanoparticles for the treatment of multi-drug resistant cancer. PloS one 2011, 6(9):e24075.

93. Milane L, Duan ZF, Amiji M: Pharmacokinetics and biodistribution of lonidamine/paclitaxel loaded, EGFR-targeted nanoparticles in an orthotopic animal model of multi-drug resistant breast cancer. Nanomedicine : nanotechnology, biology, and medicine 2011, 7(4):435-444.

94. Milane L, Duan Z, Amiji M: Development of EGFR-targeted polymer blend nanocarriers for combination paclitaxel/lonidamine delivery to treat multi-drug resistance in human breast and ovarian tumor cells. Molecular pharmaceutics 2011, 8(1):185-203.

95. Nakano A, Tsuji D, Miki H, Cui Q, El Sayed SM, Ikegame A, Oda A, Amou H, Nakamura S, Harada $T$ et al: Glycolysis inhibition inactivates $A B C$ transporters to restore drug sensitivity in malignant cells. PloS one 2011, 6(11):e27222.

96. Xu RH, Pelicano H, Zhou Y, Carew JS, Feng L, Bhalla KN, Keating MJ, Huang P: Inhibition of glycolysis in cancer cells: a novel strategy to overcome drug resistance associated with mitochondrial respiratory defect and hypoxia. Cancer research 2005, 65(2):613-621. 
97. Cao X, Bloomston M, Zhang T, Frankel WL, Jia G, Wang B, Hall NC, Koch RM, Cheng H, Knopp $\mathrm{MV}$ et al: Synergistic antipancreatic tumor effect by simultaneously targeting hypoxic cancer cells with HSP90 inhibitor and glycolysis inhibitor. Clinical cancer research : an official journal of the American Association for Cancer Research 2008, 14(6):1831-1839.

98. Ko YH, Smith BL, Wang Y, Pomper MG, Rini DA, Torbenson MS, Hullihen J, Pedersen PL: Advanced cancers: eradication in all cases using 3-bromopyruvate therapy to deplete ATP. Biochemical and biophysical research communications 2004, 324(1):269-275.

99. Zhou Y, Tozzi F, Chen J, Fan F, Xia L, Wang J, Gao G, Zhang A, Xia X, Brasher H et al: Intracellular ATP levels are a pivotal determinant of chemoresistance in colon cancer cells. Cancer research 2012, 72(1):304-314.

100. Ko YH, Pedersen PL, Geschwind JF: Glucose catabolism in the rabbit VX2 tumor model for liver cancer: characterization and targeting hexokinase. Cancer letters 2001, 173(1):83-91.

101. Shoshan MC: 3-Bromopyruvate: targets and outcomes. Journal of bioenergetics and biomembranes 2012, 44(1):7-15.

102. Ganapathy-Kanniappan S, Kunjithapatham R, Geschwind JF: Anticancer efficacy of the metabolic blocker 3-bromopyruvate: specific molecular targeting. Anticancer research 2013, 33(1):13-20.

103. Baltazar F, Pinheiro C, Morais-Santos F, Azevedo-Silva J, Queiros O, Preto A, Casal M: Monocarboxylate transporters as targets and mediators in cancer therapy response. Histology and histopathology 2014.

104. Birsoy K, Wang T, Possemato R, Yilmaz OH, Koch CE, Chen WW, Hutchins AW, Gultekin Y, Peterson TR, Carette JE et al: MCT1-mediated transport of a toxic molecule is an effective strategy for targeting glycolytic tumors. Nature genetics 2013, 45(1):104-108.

105. Ko YH, Verhoeven HA, Lee MJ, Corbin DJ, Vogl TJ, Pedersen PL: A translational study "case report" on the small molecule "energy blocker" 3-bromopyruvate (3BP) as a potent anticancer agent: from bench side to bedside. Journal of bioenergetics and biomembranes 2012, 44(1):163-170.

106. Hulleman E, Kazemier KM, Holleman A, VanderWeele DJ, Rudin CM, Broekhuis MJ, Evans WE, Pieters R, Den Boer ML: Inhibition of glycolysis modulates prednisolone resistance in acute lymphoblastic leukemia cells. Blood 2009, 113(9):2014-2021.

107. Ros S, Schulze A: Balancing glycolytic flux: the role of 6-phosphofructo-2-kinase/fructose 2,6-bisphosphatases in cancer metabolism. Cancer \& metabolism 2013, 1(1):8.

108. Atsumi T, Chesney J, Metz C, Leng L, Donnelly S, Makita Z, Mitchell R, Bucala R: High expression of inducible 6-phosphofructo-2-kinase/fructose-2,6-bisphosphatase (iPFK-2; PFKFB3) in human cancers. Cancer research 2002, 62(20):5881-5887.

109. Kessler R, Bleichert F, Warnke JP, Eschrich K: 6-Phosphofructo-2-kinase/fructose-2,6bisphosphatase (PFKFB3) is up-regulated in high-grade astrocytomas. Journal of neurooncology 2008, 86(3):257-264.

110. Bobarykina AY, Minchenko DO, Opentanova IL, Moenner M, Caro J, Esumi H, Minchenko OH: Hypoxic regulation of PFKFB-3 and PFKFB-4 gene expression in gastric and pancreatic cancer cell lines and expression of PFKFB genes in gastric cancers. Acta biochimica Polonica 2006, 53(4):789-799.

111. Calvo MN, Bartrons R, Castano E, Perales JC, Navarro-Sabate A, Manzano A: PFKFB3 gene silencing decreases glycolysis, induces cell-cycle delay and inhibits anchorage-independent growth in HeLa cells. FEBS letters 2006, 580(13):3308-3314.

112. Yalcin A, Clem BF, Imbert-Fernandez Y, Ozcan SC, Peker S, O'Neal J, Klarer AC, Clem AL, Telang $S$, Chesney J: 6-Phosphofructo-2-kinase (PFKFB3) promotes cell cycle progression and suppresses apoptosis via Cdk1-mediated phosphorylation of p27. Cell death \& disease 2014, 5:e1337.

113. De Bock K, Georgiadou M, Schoors S, Kuchnio A, Wong BW, Cantelmo AR, Quaegebeur A, Ghesquiere B, Cauwenberghs S, Eelen $\mathrm{G}$ et al: Role of PFKFB3-driven glycolysis in vessel sprouting. Cell 2013, 154(3):651-663.

114. Clem B, Telang S, Clem A, Yalcin A, Meier J, Simmons A, Rasku MA, Arumugam S, Dean WL, Eaton J et al: Small-molecule inhibition of 6-phosphofructo-2-kinase activity suppresses glycolytic flux and tumor growth. Molecular cancer therapeutics 2008, 7(1):110-120. 
115. Klarer AC, O'Neal J, Imbert-Fernandez Y, Clem A, Ellis SR, Clark J, Clem B, Chesney J, Telang S: Inhibition of 6-phosphofructo-2-kinase (PFKFB3) induces autophagy as a survival mechanism. Cancer \& metabolism 2014, 2(1):2.

116. Clem BF, O'Neal J, Tapolsky G, Clem AL, Imbert-Fernandez Y, Kerr DA, 2nd, Klarer AC, Redman R, Miller DM, Trent JO et al: Targeting 6-phosphofructo-2-kinase (PFKFB3) as a therapeutic strategy against cancer. Molecular cancer therapeutics 2013, 12(8):1461-1470.

117. Schoors S, De Bock K, Cantelmo AR, Georgiadou M, Ghesquiere B, Cauwenberghs S, Kuchnio A, Wong BW, Quaegebeur A, Goveia J et al: Partial and transient reduction of glycolysis by PFKFB3 blockade reduces pathological angiogenesis. Cell Metab 2014, 19(1):37-48.

118. Telang S, Clem BF, Klarer AC, Clem AL, Trent JO, Bucala R, Chesney J: Small molecule inhibition of 6-phosphofructo-2-kinase suppresses t cell activation. Journal of translational medicine 2012, 10:95.

119. Christofk HR, Vander Heiden MG, Harris MH, Ramanathan A, Gerszten RE, Wei R, Fleming MD, Schreiber SL, Cantley LC: The M2 splice isoform of pyruvate kinase is important for cancer metabolism and tumour growth. Nature 2008, 452(7184):230-233.

120. Iqbal MA, Gupta V, Gopinath P, Mazurek S, Bamezai RN: Pyruvate kinase M2 and cancer: an updated assessment. FEBS letters 2014, 588(16):2685-2692.

121. Dombrauckas JD, Santarsiero BD, Mesecar AD: Structural basis for tumor pyruvate kinase M2 allosteric regulation and catalysis. Biochemistry 2005, 44(27):9417-9429.

122. Li Z, Yang P, Li Z: The multifaceted regulation and functions of PKM2 in tumor progression. Biochimica et biophysica acta 2014, 1846(2):285-296.

123. Anastasiou D, Yu Y, Israelsen WJ, Jiang JK, Boxer MB, Hong BS, Tempel W, Dimov S, Shen M, Jha $A$ et al: Pyruvate kinase $M 2$ activators promote tetramer formation and suppress tumorigenesis. Nature chemical biology 2012, 8(10):839-847.

124. Kung C, Hixon J, Choe S, Marks K, Gross S, Murphy E, DeLaBarre B, Cianchetta G, Sethumadhavan S, Wang $X$ et al: Small molecule activation of PKM2 in cancer cells induces serine auxotrophy. Chemistry \& biology 2012, 19(9):1187-1198.

125. Yang W, Xia Y, Ji H, Zheng Y, Liang J, Huang W, Gao X, Aldape K, Lu Z: Nuclear PKM2 regulates beta-catenin transactivation upon EGFR activation. Nature 2011, 480(7375):118122.

126. Granchi C, Paterni I, Rani R, Minutolo F: Small-molecule inhibitors of human LDH5. Future medicinal chemistry 2013, 5(16):1967-1991.

127. Doherty JR, Cleveland JL: Targeting lactate metabolism for cancer therapeutics. The Journal of clinical investigation 2013, 123(9):3685-3692.

128. Firth JD, Ebert BL, Ratcliffe PJ: Hypoxic regulation of lactate dehydrogenase A. Interaction between hypoxia-inducible factor 1 and cAMP response elements. The Journal of biological chemistry 1995, 270(36):21021-21027.

129. Miao P, Sheng S, Sun X, Liu J, Huang G: Lactate dehydrogenase A in cancer: a promising target for diagnosis and therapy. IUBMB life 2013, 65(11):904-910.

130. Teke HU, Basak M, Teke D, Kanbay M: Serum Level of Lactate Dehydrogenase is a Useful Clinical Marker to Monitor Progressive Multiple Myeloma Diseases: A Case Report. Turkish journal of haematology : official journal of Turkish Society of Haematology 2014, 31(1):84-87.

131. Yu Y, Deck JA, Hunsaker LA, Deck LM, Royer RE, Goldberg E, Vander Jagt DL: Selective active site inhibitors of human lactate dehydrogenases A4, B4, and C4. Biochemical pharmacology 2001, 62(1):81-89.

132. Baggstrom MQ, Qi Y, Koczywas M, Argiris A, Johnson EA, Millward MJ, Murphy SC, Erlichman C, Rudin CM, Govindan R: A phase II study of AT-101 (Gossypol) in chemotherapy-sensitive recurrent extensive-stage small cell lung cancer. Journal of thoracic oncology : official publication of the International Association for the Study of Lung Cancer 2011, 6(10):17571760.

133. Heist RS, Fain J, Chinnasami B, Khan W, Molina JR, Sequist LV, Temel JS, Fidias P, Brainerd V, Leopold L et al: Phase I/II study of AT-101 with topotecan in relapsed and refractory small cell lung cancer. Journal of thoracic oncology : official publication of the International Association for the Study of Lung Cancer 2010, 5(10):1637-1643.

134. Le A, Cooper CR, Gouw AM, Dinavahi R, Maitra A, Deck LM, Royer RE, Vander Jagt DL, Semenza GL, Dang CV: Inhibition of lactate dehydrogenase $A$ induces oxidative stress and 
inhibits tumor progression. Proceedings of the National Academy of Sciences of the United States of America 2010, 107(5):2037-2042.

135. Granchi C, Roy S, Giacomelli C, Macchia M, Tuccinardi T, Martinelli A, Lanza M, Betti L, Giannaccini G, Lucacchini A et al: Discovery of $\mathbf{N}$-hydroxyindole-based inhibitors of human lactate dehydrogenase isoform A (LDH-A) as starvation agents against cancer cells. Journal of medicinal chemistry 2011, 54(6):1599-1612.

136. Pinheiro C, Longatto-Filho A, Azevedo-Silva J, Casal M, Schmitt FC, Baltazar F: Role of monocarboxylate transporters in human cancers: state of the art. Journal of bioenergetics and biomembranes 2012, 44(1):127-139.

137. Adijanto J, Philp NJ: The SLC16A family of monocarboxylate transporters (MCTs)-physiology and function in cellular metabolism, pH homeostasis, and fluid transport. Current topics in membranes 2012, 70:275-311.

138. Sonveaux P, Vegran F, Schroeder T, Wergin MC, Verrax J, Rabbani ZN, De Saedeleer CJ, Kennedy KM, Diepart C, Jordan BF et al: Targeting lactate-fueled respiration selectively kills hypoxic tumor cells in mice. The Journal of clinical investigation 2008, 118(12):3930-3942.

139. Ovens MJ, Davies AJ, Wilson MC, Murray CM, Halestrap AP: AR-C155858 is a potent inhibitor of monocarboxylate transporters MCT1 and MCT2 that binds to an intracellular site involving transmembrane helices 7-10. The Biochemical journal 2010, 425(3):523-530.

140. Enerson BE, Drewes LR: Molecular features, regulation, and function of monocarboxylate transporters: implications for drug delivery. Journal of pharmaceutical sciences 2003, 92(8):1531-1544.

141. Miranda-Goncalves V, Honavar M, Pinheiro C, Martinho O, Pires MM, Pinheiro C, Cordeiro M, Bebiano G, Costa P, Palmeirim I et al: Monocarboxylate transporters (MCTs) in gliomas: expression and exploitation as therapeutic targets. Neuro-oncology 2013, 15(2):172-188.

142. Morais-Santos F, Miranda-Goncalves V, Pinheiro S, Vieira AF, Paredes J, Schmitt FC, Baltazar $\mathrm{F}$, Pinheiro C: Differential sensitivities to lactate transport inhibitors of breast cancer cell lines. Endocrine-related cancer 2014, 21(1):27-38.

143. Le Floch R, Chiche J, Marchiq I, Naiken T, Ilc K, Murray CM, Critchlow SE, Roux D, Simon MP, Pouyssegur J: CD147 subunit of lactate/H+ symporters MCT1 and hypoxia-inducible MCT4 is critical for energetics and growth of glycolytic tumors. Proceedings of the National Academy of Sciences of the United States of America 2011, 108(40):16663-16668.

144. Afonso J, Santos LL, Miranda-Goncalves V, Morais A, Amaro T, Longatto-Filho A, Baltazar F: CD147 and MCT1-potential partners in bladder cancer aggressiveness and cisplatin resistance. Molecular carcinogenesis 2014.

145. de Oliveira AT, Pinheiro C, Longatto-Filho A, Brito MJ, Martinho O, Matos D, Carvalho AL, Vazquez VL, Silva TB, Scapulatempo C et al: Co-expression of monocarboxylate transporter 1 (MCT1) and its chaperone (CD147) is associated with low survival in patients with gastrointestinal stromal tumors (GISTs). Journal of bioenergetics and biomembranes 2012, 44(1):171-178.

146. Pertega-Gomes N, Vizcaino JR, Miranda-Goncalves V, Pinheiro C, Silva J, Pereira H, Monteiro $\mathrm{P}$, Henrique RM, Reis RM, Lopes C et al: Monocarboxylate transporter 4 (MCT4) and CD147 overexpression is associated with poor prognosis in prostate cancer. BMC cancer 2011, 11:312.

147. Pinheiro C, Longatto-Filho A, Simoes K, Jacob CE, Bresciani CJ, Zilberstein B, Cecconello I, Alves VA, Schmitt $F$, Baltazar F: The prognostic value of CD147/EMMPRIN is associated with monocarboxylate transporter 1 co-expression in gastric cancer. European journal of cancer (Oxford, England : 1990) 2009, 45(13):2418-2424.

148. Pinheiro C, Longatto-Filho A, Pereira SM, Etlinger D, Moreira MA, Jube LF, Queiroz GS, Schmitt F, Baltazar F: Monocarboxylate transporters 1 and 4 are associated with CD147 in cervical carcinoma. Disease markers 2009, 26(3):97-103.

149. Chen H, Wang L, Beretov J, Hao J, Xiao W, Li Y: Co-expression of CD147/EMMPRIN with monocarboxylate transporters and multiple drug resistance proteins is associated with epithelial ovarian cancer progression. Clinical \& experimental metastasis 2010, 27(8):557569.

150. Pinheiro C, Albergaria A, Paredes J, Sousa B, Dufloth R, Vieira D, Schmitt F, Baltazar F: Monocarboxylate transporter 1 is up-regulated in basal-like breast carcinoma. Histopathology 2010, 56(7):860-867. 
151. Slomiany MG, Grass GD, Robertson AD, Yang XY, Maria BL, Beeson C, Toole BP: Hyaluronan, CD44, and emmprin regulate lactate efflux and membrane localization of monocarboxylate transporters in human breast carcinoma cells. Cancer research 2009, 69(4):1293-1301.

152. Baba M, Inoue M, Itoh K, Nishizawa Y: Blocking CD147 induces cell death in cancer cells through impairment of glycolytic energy metabolism. Biochemical and biophysical research communications 2008, 374(1):111-116.

153. Schneiderhan W, Scheler M, Holzmann KH, Marx M, Gschwend JE, Bucholz M, Gress TM, Seufferlein T, Adler G, Oswald F: CD147 silencing inhibits lactate transport and reduces malignant potential of pancreatic cancer cells in in vivo and in vitro models. Gut 2009, 58(10):1391-1398.

154. Xiong L, Edwards CK, 3rd, Zhou L: The biological function and clinical utilization of CD147 in human diseases: a review of the current scientific literature. International journal of molecular sciences 2014, 15(10):17411-17441.

155. Kasinrerk W, Tokrasinwit N, Phunpae P: CD147 monoclonal antibodies induce homotypic cell aggregation of monocytic cell line U937 via LFA-1/ICAM-1 pathway. Immunology 1999, 96(2):184-192.

156. Patel MS, Nemeria NS, Furey W, Jordan F: The pyruvate dehydrogenase complexes: structure-based function and regulation. The Journal of biological chemistry 2014, 289(24):16615-16623.

157. Dunbar EM, Coats BS, Shroads AL, Langaee T, Lew A, Forder JR, Shuster JJ, Wagner DA, Stacpoole PW: Phase 1 trial of dichloroacetate (DCA) in adults with recurrent malignant brain tumors. Investigational new drugs 2014, 32(3):452-464.

158. Whitehouse S, Randle PJ: Activation of pyruvate dehydrogenase in perfused rat heart by dichloroacetate (Short Communication). The Biochemical journal 1973, 134(2):651-653.

159. Knoechel TR, Tucker AD, Robinson CM, Phillips C, Taylor W, Bungay PJ, Kasten SA, Roche TE, Brown DG: Regulatory roles of the $\mathbf{N}$-terminal domain based on crystal structures of human pyruvate dehydrogenase kinase 2 containing physiological and synthetic ligands. Biochemistry 2006, 45(2):402-415.

160. Michelakis ED, Webster L, Mackey JR: Dichloroacetate (DCA) as a potential metabolictargeting therapy for cancer. British journal of cancer 2008, 99(7):989-994.

161. Bonnet S, Archer SL, Allalunis-Turner J, Haromy A, Beaulieu C, Thompson R, Lee CT, Lopaschuk GD, Puttagunta L, Bonnet $\mathrm{S}$ et al: A mitochondria-K+ channel axis is suppressed in cancer and its normalization promotes apoptosis and inhibits cancer growth. Cancer cell 2007, 11(1):37-51.

162. Stacpoole PW: The pharmacology of dichloroacetate. Metabolism: clinical and experimental 1989, 38(11):1124-1144.

163. Michelakis ED, Sutendra G, Dromparis P, Webster L, Haromy A, Niven E, Maguire C, Gammer TL, Mackey JR, Fulton D et al: Metabolic modulation of glioblastoma with dichloroacetate. Science translational medicine 2010, 2(31):31ra34.

164. Kankotia S, Stacpoole PW: Dichloroacetate and cancer: New home for an orphan drug? Biochimica et biophysica acta 2014.

165. Garon EB, Christofk HR, Hosmer W, Britten CD, Bahng A, Crabtree MJ, Hong CS, Kamranpour $\mathrm{N}$, Pitts S, Kabbinavar F et al: Dichloroacetate should be considered with platinum-based chemotherapy in hypoxic tumors rather than as a single agent in advanced non-small cell lung cancer. Journal of cancer research and clinical oncology 2014, 140(3):443-452.

166. Ganapathy-Kanniappan S, Geschwind JF: Tumor glycolysis as a target for cancer therapy: progress and prospects. Molecular cancer 2013, 12:152.

167. Hasmim M, Messai Y, Noman MZ, Chouaib S: [Tumor hypoxia: a key player in the regulation of stromal and anti-tumor responses]. Medecine sciences : $M / S$ 2014, 30(4):422-428.

168. De Milito A, Fais S: Tumor acidity, chemoresistance and proton pump inhibitors. Future oncology (London, England) 2005, 1(6):779-786.

169. Backos DS, Franklin CC, Reigan P: The role of glutathione in brain tumor drug resistance. Biochemical pharmacology 2012, 83(8):1005-1012.

170. Maschek G, Savaraj N, Priebe W, Braunschweiger P, Hamilton K, Tidmarsh GF, De Young LR, Lampidis TJ: 2-deoxy-D-glucose increases the efficacy of adriamycin and paclitaxel in human osteosarcoma and non-small cell lung cancers in vivo. Cancer research 2004, 64(1):31-34. 
171. Sullivan EJ, Kurtoglu M, Brenneman R, Liu H, Lampidis TJ: Targeting cisplatin-resistant human tumor cells with metabolic inhibitors. Cancer chemotherapy and pharmacology 2014, 73(2):417-427.

172. Del Bufalo D, Biroccio A, Soddu S, Laudonio N, D'Angelo C, Sacchi A, Zupi G: Lonidamine induces apoptosis in drug-resistant cells independently of the p53 gene. The Journal of clinical investigation 1996, 98(5):1165-1173.

173. Tennant DA, Duran RV, Gottlieb E: Targeting metabolic transformation for cancer therapy. Nature reviews Cancer 2010, 10(4):267-277.

174. Ianniello GP, De Cataldis G, Comella P, Scarpati MD, Maiorino A, Brancaccio L, Cioffi R, Lombardi A, Carnicelli $P$, Tinessa V: Cisplatin, epirubicin, and vindesine with or without lonidamine in the treatment of inoperable nonsmall cell lung carcinoma: a multicenter randomized clinical trial. Cancer 1996, 78(1):63-69.

175. Orlandi L, Zaffaroni N, Gornati D, Veneroni S, Silvestrini R: Potentiation of cisplatin cytotoxicity by lonidamine in primary cultures of human ovarian cancer. Anticancer research 1994, 14(3a):1161-1164.

176. Dogliotti L, Berruti A, Buniva T, Zola P, Bau MG, Farris A, Sarobba MG, Bottini A, Alquati P, Deltetto $\mathrm{F}$ et al: Lonidamine significantly increases the activity of epirubicin in patients with advanced breast cancer: results from a multicenter prospective randomized trial. Journal of clinical oncology : official journal of the American Society of Clinical Oncology 1996, 14(4):1165-1172.

177. Bean JF, Qiu YY, Yu S, Clark S, Chu F, Madonna MB: Glycolysis inhibition and its effect in doxorubicin resistance in neuroblastoma. Journal of pediatric surgery 2014, 49(6):981-984; discussion 984.

178. Zhai X, Yang Y, Wan J, Zhu R, Wu Y: Inhibition of LDH-A by oxamate induces G2/M arrest, apoptosis and increases radiosensitivity in nasopharyngeal carcinoma cells. Oncology reports 2013, 30(6):2983-2991.

179. Hua G, Liu Y, Li X, Xu P, Luo Y: Targeting glucose metabolism in chondrosarcoma cells enhances the sensitivity to doxorubicin through the inhibition of lactate dehydrogenase-A. Oncology reports 2014, 31(6):2727-2734.

180. Li X, Zhao H, Zhou X, Song L: Inhibition of lactate dehydrogenase A by microRNA34a resensitizes colon cancer cells to 5fluorouracil. Molecular medicine reports 2015, 11(1):577582.

181. Zheng MF, Shen SY, Huang WD: DCA increases the antitumor effects of capecitabine in a mouse B16 melanoma allograft and a human non-small cell lung cancer A549 xenograft. Cancer chemotherapy and pharmacology 2013, 72(5):1031-1041.

182. Fiebiger W, Olszewski U, Ulsperger E, Geissler K, Hamilton G: In vitro cytotoxicity of novel platinum-based drugs and dichloroacetate against lung carcinoid cell lines. Clinical \& translational oncology : official publication of the Federation of Spanish Oncology Societies and of the National Cancer Institute of Mexico 2011, 13(1):43-49.

183. Xuan Y, Hur H, Ham IH, Yun J, Lee JY, Shim W, Kim YB, Lee G, Han SU, Cho YK: Dichloroacetate attenuates hypoxia-induced resistance to 5 -fluorouracil in gastric cancer through the regulation of glucose metabolism. Experimental cell research 2014, 321(2):219230.

184. Kumar A, Kant S, Singh SM: Antitumor and chemosensitizing action of dichloroacetate implicates modulation of tumor microenvironment: a role of reorganized glucose metabolism, cell survival regulation and macrophage differentiation. Toxicology and applied pharmacology 2013, 273(1):196-208.

185. Zong WX, Ditsworth D, Bauer DE, Wang ZQ, Thompson CB: Alkylating DNA damage stimulates a regulated form of necrotic cell death. Genes \& development 2004, 18(11):12721282.

186. Lemmon MA, Schlessinger J: Cell signaling by receptor tyrosine kinases. Cell 2010, 141(7):1117-1134.

187. Blume-Jensen P, Hunter T: Oncogenic kinase signalling. Nature 2001, 411(6835):355-365.

188. Amit I, Wides R, Yarden Y: Evolvable signaling networks of receptor tyrosine kinases: relevance of robustness to malignancy and to cancer therapy. Molecular systems biology 2007, 3:151. 
189. Drevs J, Medinger M, Schmidt-Gersbach C, Weber R, Unger C: Receptor tyrosine kinases: the main targets for new anticancer therapy. Current drug targets 2003, 4(2):113-121.

190. Jurgensmeier JM, Eder JP, Herbst RS: New strategies in personalized medicine for solid tumors: molecular markers and clinical trial designs. Clinical cancer research : an official journal of the American Association for Cancer Research 2014, 20(17):4425-4435.

191. Stegmeier F, Warmuth M, Sellers WR, Dorsch M: Targeted cancer therapies in the twentyfirst century: lessons from imatinib. Clinical pharmacology and therapeutics 2010, 87(5):543-552.

192. Jonkers J, Berns A: Oncogene addiction: sometimes a temporary slavery. Cancer cell 2004, 6(6):535-538.

193. Chong CR, Janne PA: The quest to overcome resistance to EGFR-targeted therapies in cancer. Nat Med 2013, 19(11):1389-1400.

194. Hynes NE, Lane HA: ERBB receptors and cancer: the complexity of targeted inhibitors. Nature reviews Cancer 2005, 5(5):341-354.

195. Xu AM, Huang PH: Receptor tyrosine kinase coactivation networks in cancer. Cancer research 2010, 70(10):3857-3860.

196. Shawver LK, Slamon D, Ullrich A: Smart drugs: tyrosine kinase inhibitors in cancer therapy. Cancer cell 2002, 1(2):117-123.

197. Demetri GD, von Mehren M, Blanke CD, Van den Abbeele AD, Eisenberg B, Roberts PJ, Heinrich MC, Tuveson DA, Singer S, Janicek M et al: Efficacy and safety of imatinib mesylate in advanced gastrointestinal stromal tumors. The New England journal of medicine 2002, 347(7):472-480.

198. Mason EF, Zhao Y, Goraksha-Hicks P, Coloff JL, Gannon H, Jones SN, Rathmell JC: Aerobic glycolysis suppresses $\mathrm{p} 53$ activity to provide selective protection from apoptosis upon loss of growth signals or inhibition of BCR-Abl. Cancer research 2010, 70(20):8066-8076.

199. Gottschalk S, Anderson N, Hainz C, Eckhardt SG, Serkova NJ: Imatinib (STI571)-mediated changes in glucose metabolism in human leukemia BCR-ABL-positive cells. Clinical cancer research : an official journal of the American Association for Cancer Research 2004, 10(19):6661-6668.

200. Klawitter J, Kominsky DJ, Brown JL, Klawitter J, Christians U, Leibfritz D, Melo JV, Eckhardt SG, Serkova NJ: Metabolic characteristics of imatinib resistance in chronic myeloid leukaemia cells. British journal of pharmacology 2009, 158(2):588-600.

201. Kluza J, Jendoubi M, Ballot C, Dammak A, Jonneaux A, Idziorek T, Joha S, Dauphin V, MaletMartino M, Balayssac $S$ et al: Exploiting mitochondrial dysfunction for effective elimination of imatinib-resistant leukemic cells. PloS one 2011, 6(7):e21924.

202. Kominsky DJ, Klawitter J, Brown JL, Boros LG, Melo JV, Eckhardt SG, Serkova NJ: Abnormalities in glucose uptake and metabolism in imatinib-resistant human BCR-ABLpositive cells. Clinical cancer research : an official journal of the American Association for Cancer Research 2009, 15(10):3442-3450.

203. Boros LG, Cascante M, Lee WN: Metabolic profiling of cell growth and death in cancer: applications in drug discovery. Drug Discov Today 2002, 7(6):364-372.

204. Serkova N, Boros LG: Detection of resistance to imatinib by metabolic profiling: clinical and drug development implications. Am J Pharmacogenomics 2005, 5(5):293-302.

205. Barnes K, McIntosh E, Whetton AD, Daley GQ, Bentley J, Baldwin SA: Chronic myeloid leukaemia: an investigation into the role of Bcr-Abl-induced abnormalities in glucose transport regulation. Oncogene 2005, 24(20):3257-3267.

206. Boren J, Cascante M, Marin S, Comin-Anduix B, Centelles JJ, Lim S, Bassilian S, Ahmed S, Lee WN, Boros LG: Gleevec (STI571) influences metabolic enzyme activities and glucose carbon flow toward nucleic acid and fatty acid synthesis in myeloid tumor cells. The Journal of biological chemistry 2001, 276(41):37747-37753.

207. Bentley J, Walker I, Mclntosh E, Whetton AD, Owen-Lynch PJ, Baldwin SA: Glucose transport regulation by $\mathrm{p} 210 \mathrm{Bcr}-\mathrm{Abl}$ in a chronic myeloid leukaemia model. British journal of haematology 2001, 112(1):212-215.

208. Bentley J, Itchayanan D, Barnes K, McIntosh E, Tang X, Downes CP, Holman GD, Whetton AD, Owen-Lynch PJ, Baldwin SA: Interleukin-3-mediated cell survival signals include phosphatidylinositol 3-kinase-dependent translocation of the glucose transporter GLUT1 to the cell surface. The Journal of biological chemistry 2003, 278(41):39337-39348. 
209. Zhao F, Mancuso A, Bui TV, Tong X, Gruber JJ, Swider CR, Sanchez PV, Lum JJ, Sayed N, Melo JV et al: Imatinib resistance associated with BCR-ABL upregulation is dependent on HIF-

1alpha-induced metabolic reprograming. Oncogene 2010, 29(20):2962-2972.

210. Giuntoli S, Tanturli M, Di Gesualdo F, Barbetti V, Rovida E, Dello Sbarba P: Glucose availability in hypoxia regulates the selection of chronic myeloid leukemia progenitor subsets with different resistance to imatinib-mesylate. Haematologica 2011, 96(2):204-212.

211. Martinez Marignac VL, Smith S, Toban N, Bazile M, Aloyz R: Resistance to Dasatinib in primary chronic lymphocytic leukemia lymphocytes involves AMPK-mediated energetic reprogramming. Oncotarget 2013, 4(12):2550-2566.

212. Fumarola C, Caffarra C, La Monica S, Galetti M, Alfieri RR, Cavazzoni A, Galvani E, Generali D, Petronini PG, Bonelli MA: Effects of sorafenib on energy metabolism in breast cancer cells: role of AMPK-mTORC1 signaling. Breast cancer research and treatment 2013, 141(1):67-78.

213. Hudson CD, Hagemann T, Mather SJ, Avril N: Resistance to the tyrosine kinase inhibitor axitinib is associated with increased glucose metabolism in pancreatic adenocarcinoma. Cell death \& disease 2014, 5:e1160.

214. Makinoshima H, Takita M, Matsumoto S, Yagishita A, Owada S, Esumi H, Tsuchihara K: Epidermal Growth Factor Receptor (EGFR) Signaling Regulates Global Metabolic Pathways in EGFR-mutated Lung Adenocarcinoma. The Journal of biological chemistry 2014, 289(30):20813-20823.

215. Velpula KK, Bhasin A, Asuthkar S, Tsung AJ: Combined targeting of PDK1 and EGFR triggers regression of glioblastoma by reversing the Warburg effect. Cancer research 2013, 73(24):7277-7289.

216. Su H, Bodenstein C, Dumont RA, Seimbille Y, Dubinett S, Phelps ME, Herschman H, Czernin J, Weber W: Monitoring tumor glucose utilization by positron emission tomography for the prediction of treatment response to epidermal growth factor receptor kinase inhibitors. Clinical cancer research : an official journal of the American Association for Cancer Research 2006, 12(19):5659-5667.

217. Li X, Lu Y, Liang K, Pan T, Mendelsohn J, Fan Z: Requirement of hypoxia-inducible factor1alpha down-regulation in mediating the antitumor activity of the anti-epidermal growth factor receptor monoclonal antibody cetuximab. Molecular cancer therapeutics 2008, 7(5):1207-1217.

218. Lu Y, Liang K, Li X, Fan Z: Responses of cancer cells with wild-type or tyrosine kinase domain-mutated epidermal growth factor receptor (EGFR) to EGFR-targeted therapy are linked to downregulation of hypoxia-inducible factor-1alpha. Molecular cancer 2007, 6:63.

219. Lu H, Li X, Luo Z, Liu J, Fan Z: Cetuximab reverses the Warburg effect by inhibiting HIF-1regulated LDH-A. Molecular cancer therapeutics 2013, 12(10):2187-2199.

220. Monteleone F, Rosa R, Vitale M, D'Ambrosio C, Succoio M, Formisano L, Nappi L, Romano $\mathrm{MF}$, Scaloni A, Tortora $\mathrm{G}$ et al: Increased anaerobic metabolism is a distinctive signature in a colorectal cancer cellular model of resistance to antiepidermal growth factor receptor antibody. Proteomics 2013, 13(5):866-877.

221. Komurov K, Tseng JT, Muller M, Seviour EG, Moss TJ, Yang L, Nagrath D, Ram PT: The glucose-deprivation network counteracts lapatinib-induced toxicity in resistant ErbB2positive breast cancer cells. Molecular systems biology 2012, 8:596.

222. Kim SM, Yun MR, Hong YK, Solca F, Kim JH, Kim HJ, Cho BC: Glycolysis inhibition sensitizes non-small cell lung cancer with T790M mutation to irreversible EGFR inhibitors via translational suppression of Mcl-1 by AMPK activation. Molecular cancer therapeutics 2013, 12(10):2145-2156.

223. Chapman PB, Hauschild A, Robert C, Haanen JB, Ascierto P, Larkin J, Dummer R, Garbe C, Testori A, Maio $M$ et al: Improved survival with vemurafenib in melanoma with BRAF V600E mutation. The New England journal of medicine 2011, 364(26):2507-2516.

224. Lee MH, Lee SE, Kim DW, Ryu MJ, Kim SJ, Kim SJ, Kim YK, Park JH, Kweon GR, Kim JM et al: Mitochondrial localization and regulation of BRAFV600E in thyroid cancer: a clinically used RAF inhibitor is unable to block the mitochondrial activities of BRAFV600E. The Journal of clinical endocrinology and metabolism 2011, 96(1):E19-30.

225. Parmenter TJ, Kleinschmidt M, Kinross KM, Bond ST, Li J, Kaadige MR, Rao A, Sheppard KE, Hugo W, Pupo GM et al: Response of BRAF-mutant melanoma to BRAF inhibition is 
mediated by a network of transcriptional regulators of glycolysis. Cancer discovery 2014, 4(4):423-433.

226. Falck Miniotis M, Arunan V, Eykyn TR, Marais R, Workman P, Leach MO, Beloueche-Babari M: MEK1/2 inhibition decreases lactate in BRAF-driven human cancer cells. Cancer research 2013, 73(13):4039-4049.

227. Kluza J, Corazao-Rozas P, Touil Y, Jendoubi M, Maire C, Guerreschi P, Jonneaux A, Ballot C, Balayssac $S$, Valable $S$ et al: Inactivation of the HIF-1alpha/PDK3 signaling axis drives melanoma toward mitochondrial oxidative metabolism and potentiates the therapeutic activity of pro-oxidants. Cancer research 2012, 72(19):5035-5047.

228. Strohecker AM, White E: Targeting mitochondrial metabolism by inhibiting autophagy in BRAF-driven cancers. Cancer discovery 2014, 4(7):766-772.

229. Ostergaard L, Tietze A, Nielsen T, Drasbek KR, Mouridsen K, Jespersen SN, Horsman MR: The relationship between tumor blood flow, angiogenesis, tumor hypoxia, and aerobic glycolysis. Cancer research 2013, 73(18):5618-5624.

230. Baker GJ, Yadav VN, Motsch S, Koschmann C, Calinescu AA, Mineharu Y, Camelo-Piragua SI, Orringer D, Bannykh S, Nichols WS et al: Mechanisms of glioma formation: iterative perivascular glioma growth and invasion leads to tumor progression, VEGF-independent vascularization, and resistance to antiangiogenic therapy. Neoplasia (New York, NY) 2014, 16(7):543-561.

231. Rapisarda A, Hollingshead M, Uranchimeg B, Bonomi CA, Borgel SD, Carter JP, Gehrs B, Raffeld $M$, Kinders RJ, Parchment $R$ et al: Increased antitumor activity of bevacizumab in combination with hypoxia inducible factor-1 inhibition. Molecular cancer therapeutics 2009, 8(7):1867-1877.

232. Kumar K, Wigfield S, Gee HE, Devlin CM, Singleton D, Li JL, Buffa F, Huffman M, Sinn AL, Silver $\mathrm{J}$ et al: Dichloroacetate reverses the hypoxic adaptation to bevacizumab and enhances its antitumor effects in mouse xenografts. Journal of molecular medicine 2013, 91(6):749-758.

233. Fack F, Espedal H, Keunen O, Golebiewska A, Obad N, Harter PN, Mittelbronn M, Bahr O, Weyerbrock A, Stuhr L et al: Bevacizumab treatment induces metabolic adaptation toward anaerobic metabolism in glioblastomas. Acta neuropathologica 2014.

234. Hartwich J, Orr WS, Ng CY, Spence Y, Morton C, Davidoff AM: HIF-1alpha activation mediates resistance to anti-angiogenic therapy in neuroblastoma xenografts. Journal of pediatric surgery 2013, 48(1):39-46.

235. Xu J, Wang J, Xu B, Ge H, Zhou X, Fang JY: Colorectal cancer cells refractory to anti-VEGF treatment are vulnerable to glycolytic blockade due to persistent impairment of mitochondria. Molecular cancer therapeutics 2013, 12(5):717-724.

236. Hasan MR, Ho SH, Owen DA, Tai IT: Inhibition of VEGF induces cellular senescence in colorectal cancer cells. International journal of cancer Journal international du cancer 2011, 129(9):2115-2123.

237. Hu YL, DeLay M, Jahangiri A, Molinaro AM, Rose SD, Carbonell WS, Aghi MK: Hypoxiainduced autophagy promotes tumor cell survival and adaptation to antiangiogenic treatment in glioblastoma. Cancer research 2012, 72(7):1773-1783.

238. Favaro E, Bensaad K, Chong MG, Tennant DA, Ferguson DJ, Snell C, Steers G, Turley H, Li JL, Gunther UL et al: Glucose utilization via glycogen phosphorylase sustains proliferation and prevents premature senescence in cancer cells. Cell metabolism 2012, 16(6):751-764.

239. Zhong H, Chiles K, Feldser D, Laughner E, Hanrahan C, Georgescu MM, Simons JW, Semenza GL: Modulation of hypoxia-inducible factor 1alpha expression by the epidermal growth factor/phosphatidylinositol 3-kinase/PTEN/AKT/FRAP pathway in human prostate cancer cells: implications for tumor angiogenesis and therapeutics. Cancer research 2000, 60(6):1541-1545.

240. Phillips RJ, Mestas J, Gharaee-Kermani M, Burdick MD, Sica A, Belperio JA, Keane MP, Strieter RM: Epidermal growth factor and hypoxia-induced expression of CXC chemokine receptor 4 on non-small cell lung cancer cells is regulated by the phosphatidylinositol 3kinase/PTEN/AKT/mammalian target of rapamycin signaling pathway and activation of hypoxia inducible factor-1alpha. The Journal of biological chemistry 2005, 280(23):2247322481.

241. Das B, Yeger H, Tsuchida R, Torkin R, Gee MF, Thorner PS, Shibuya M, Malkin D, Baruchel S: A hypoxia-driven vascular endothelial growth factor/Flt1 autocrine loop interacts with 
hypoxia-inducible factor-1alpha through mitogen-activated protein kinase/extracellular signal-regulated kinase 1/2 pathway in neuroblastoma. Cancer research 2005, 65(16):72677275.

242. Nilsson MB, Zage PE, Zeng L, Xu L, Cascone T, Wu HK, Saigal B, Zweidler-McKay PA, Heymach $\mathrm{JV}$ : Multiple receptor tyrosine kinases regulate HIF-1alpha and HIF-2alpha in normoxia and hypoxia in neuroblastoma: implications for antiangiogenic mechanisms of multikinase inhibitors. Oncogene 2010, 29(20):2938-2949.

243. Fiume L, Vettraino M, Manerba M, Di Stefano G: Inhibition of lactic dehydrogenase as a way to increase the anti-proliferative effect of multi-targeted kinase inhibitors. Pharmacological research : the official journal of the Italian Pharmacological Society 2011, 63(4):328-334.

244. Schulze A, Harris AL: How cancer metabolism is tuned for proliferation and vulnerable to disruption. Nature 2012, 491(7424):364-373.

245. DeBerardinis RJ, Lum JJ, Hatzivassiliou G, Thompson CB: The biology of cancer: metabolic reprogramming fuels cell growth and proliferation. Cell metabolism 2008, 7(1):11-20. 


\section{Figure legends:}

Figure 1: Main proteins of glucose metabolism explored as therapeutic targets. GLUT-1, glucose transporter 1; HK II, hexokinase II; PFKFB3, 6-phosphofructo-2kinase/fructose-2,6-biphosphatase 3; PKM, Pyruvate kinase M2, PDH, pyruvate dehydrogenase; PDK, pyruvate dehydrogenase kinase; LDH, lactate dehydrogenase; MCT1, monocarboxylate transporter 1, 2-DG, 2-Deoxy-D-glucose; DCA, Dichloroacetate.

Figure 2: Receptor tyrosine kinases (RTK) signaling pathways. Broadly, binding of a ligand activates a RTK by inducing receptor dimerization, resulting in autophosphorylation (P) of its cytoplasmic domains, with consequent phosphorylation/activation of 3 main intracellular signaling pathways. The two main strategies to block activation of RTK-mediated signaling are also represented, which include the use of selective molecules that target the extracellular ligand-binding domain [monoclonal antibodies (mAbs)], the intracellular tyrosine kinase activity or the substrate-binding region [small tyrosine kinase inhibitors (TKi)]. 


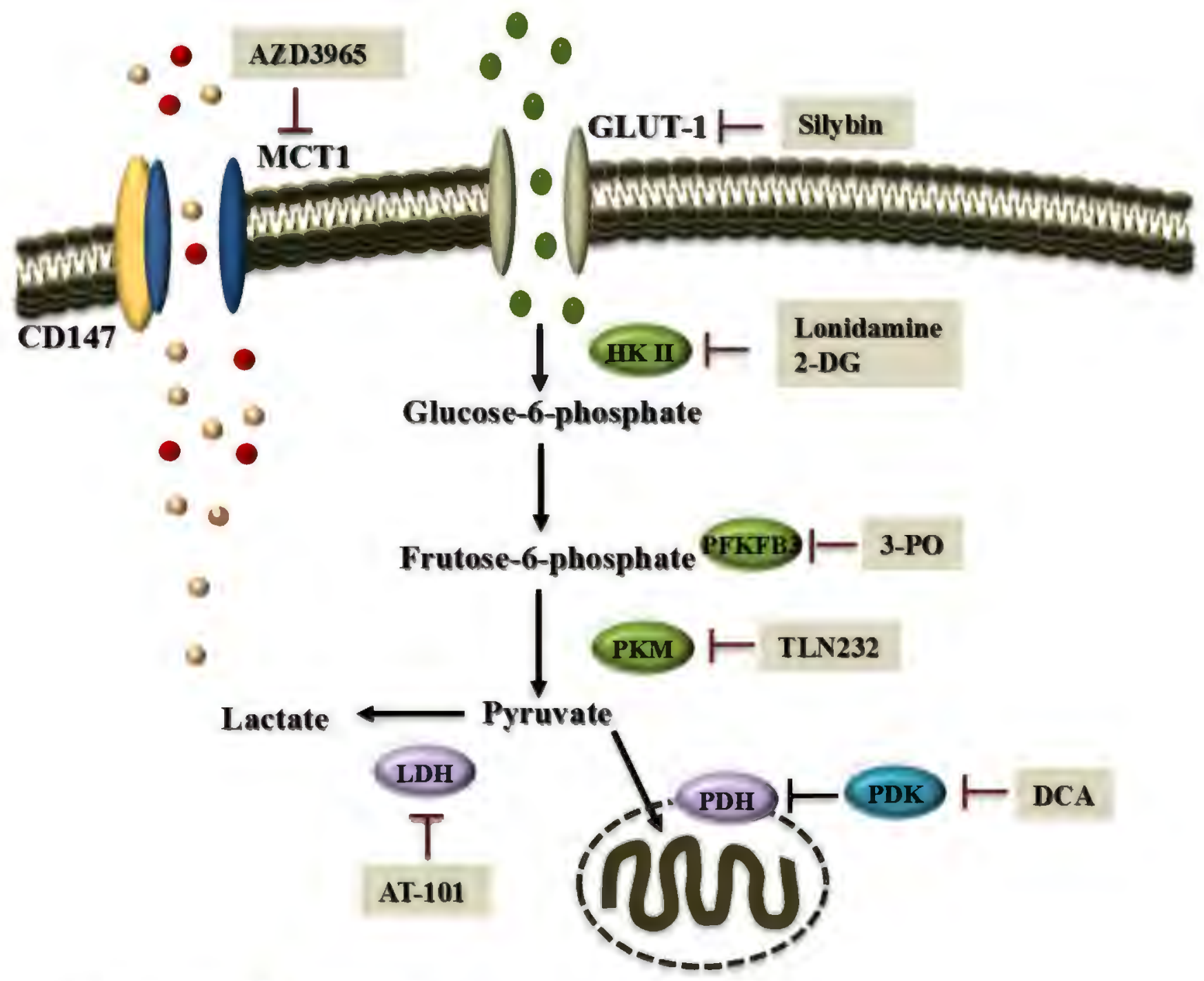

- Glucose $O$ Lactate $\mathrm{H}^{+}$ 


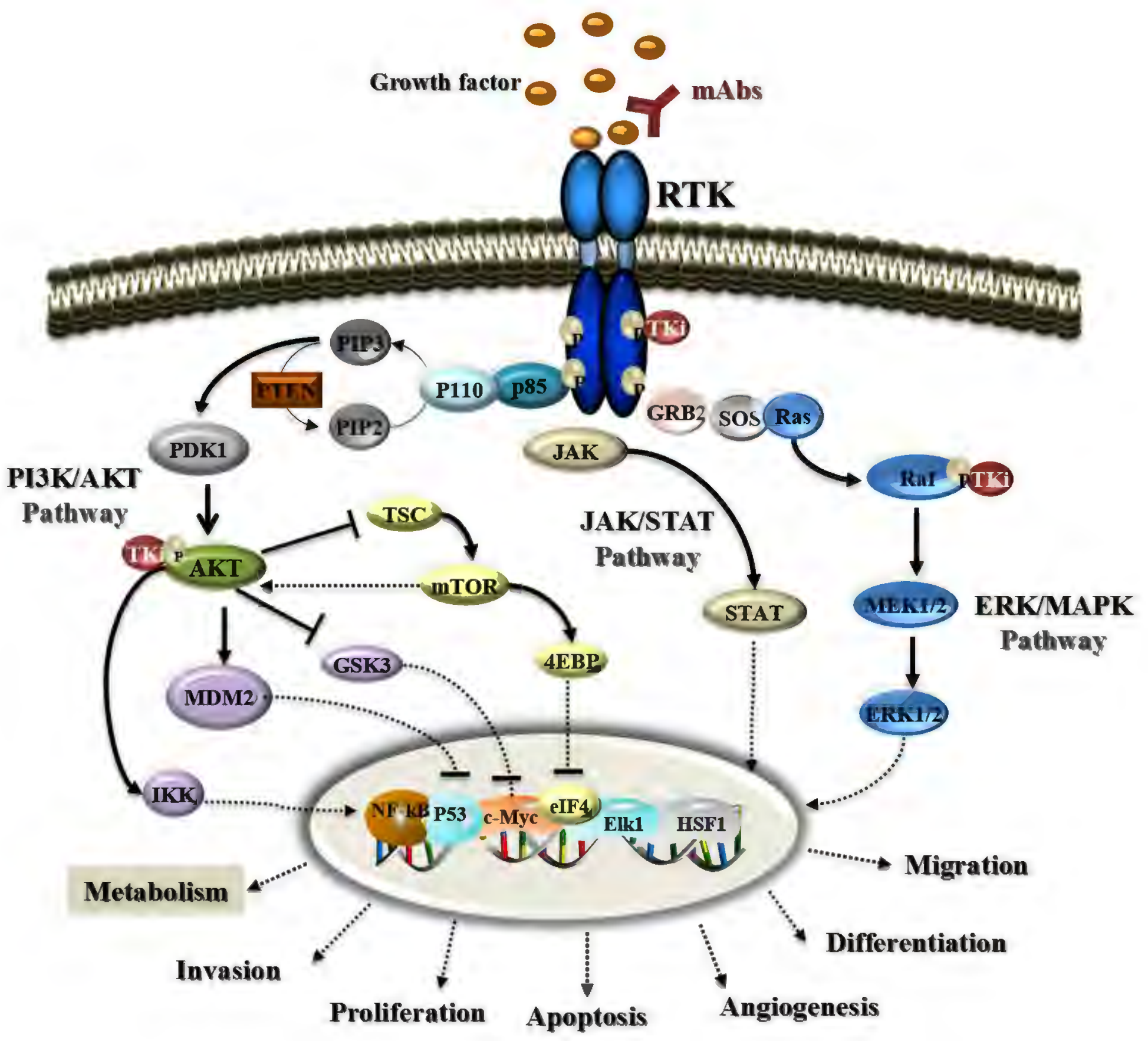

